Escobar Ávila, Julián Andrés. Proyectos de renovación urbana en el centro histórico de la ciudad de Ibagué-Colombia. Periodo 2000-2015. Apuesta política hacia un centro más rentable. GeoGraphos [En línea]. Alicante: Grupo Interdisciplinario de Estudios Críticos y de América Latina (GIECRYAL) de la Universidad de Alicante, 2 de abril de 2018, vol. 9, $\mathrm{n}^{\circ}$ 105, p. 111-140 [ISSN: 2173-1276] [DL: A 371-2013] [DOI: 10.14198/GEOGRA2018.9.105].

\title{
Ge Graphos
}

REVISTA DIGITAL

PARA ESTUDIANTES DE GEOGRAFÍA Y CIENCIAS SOCIALES

$<\underline{\text { http://web.ua.es/revista-geographos-giecryal }>}$

\section{PROYECTOS DE RENOVACIÓN URBANA EN EL CENTRO HISTÓRICO DE LA CIUDAD DE IBAGUÉ-COLOMBIA. PERIODO 2000-2015. APUESTA POLÍTICA HACIA UN CENTRO MÁS RENTABLE}

\author{
Julián Andrés Escobar Ávila ${ }^{1}$ \\ Estudiante de la Licenciatura en Ciencias Sociales \\ Universidad del Tolima (Colombia.) \\ Correo electrónico: jaescobara@ut.edu.co
}

Recibido: 2 de marzo de 2017. Devuelto para revisión: 19 de abril de 2017.

Aceptado: 2 de abril de 2018

${ }^{1}$ ID: 0000-0002-4950-2445 


\title{
RESUMEN
}

El presente artículo aborda el tema de la renovación urbana como punto neurálgico en el desarrollo de las ciudades Latinoaméricanas, específicamente el caso del centro histórico de la ciudad de Ibagué -Colombia, donde se analizarán las dinámicas sobre el impacto y consecuencias espaciales del poder político en materia de renovación urbana entre el periodo 2000-2015. Así mismo, los proyectos de renovación urbana más destacados que han transformado el paisaje de este sector y las dinámicas socioeconómicas que se han generado a partir de inversión de la empresa privada y las políticas públicas ejecutadas en los años de análisis para finalmente, estudiar el proceso de terciarización urbana denotado a través de la renovación y revitalización del centro histórico de la cuidad de Ibagué.

Palabras clave: Renovación urbana, desarrollo urbano, políticas urbanas, centro histórico, terciarización.

\section{PROJECTS OF URBAN RENEWAL IN THE HISTORICAL CENTER OF THE CITY OF IBAGUÉ-COLOMBIA. PERIOD 2000-2015. A POLICITAL COMMITMENT TOWARDS A MORE PROFITABLE CENTER}

\begin{abstract}
This article will address the theme of urban renewal as a nerve center in the development of Latin American cities, specifically the historical center of the city of Ibagué - Colombia, where dynamics on the impact and spatial consequences of Political power in urban renewal between the period 2000-2015 in the area of study. It will also address the most outstanding urban renewal projects that have transformed the landscape of this sector and the socioeconomic dynamics of the area mentioned, resulting in a strong investment situation of private enterprise based on the public policies implemented in the years of analysis. From the same, it analyzes the process of outsourcing urban denoted from the renovation and revitalization of the historical center.
\end{abstract}

Key Words: Urban Renovation, urban development, urban political, history center, outsourcing.

\section{PROJETOS DE RENOVACÃO URBANA DO CENTRO HISTÓRICO DA CIDADE DE IBAGUÉ-COLÔMBIA. PERIODO 2000-2015. COMPROMISO POLÍTICA PARA UM CENTRO MAIS RENTÁVEL}

\section{RESUMO}

Este artigo aborda a questão da renovação urbana como um ponto focal para o desenvolvimento de cidades latino-americanas, especificamente o caso do centro histórico da cidade de Ibagué Colômbia, onde a dinâmica sobre o impacto e as consequências das espacial ser analisados poder político na renovação urbana entre o período de 2000-2015 na área de estudo. Da mesma forma, projectos pendentes de renovação urbana que transformou a paisagem deste sector e dinâmicas socio-económicas da área a que se refere a serem abordados, resultando em um forte investimento situação da empresa privada de políticas 
públicas implementadas no anos de análise. Destes, terceirização de processos urbana denotado da renovação e revitalização do centro histórico é analisado.

Palavras chave: renovação urbana, o desenvolvimento urbano, políticas urbanas, histórico centro terceirização.

\section{INTRODUCCIÓN}

La renovación urbana en los centros históricos es un fenómeno característico de las ciudades contemporáneas que se manifiesta a partir de las actividades económicas sociales y políticas de las franjas urbanas centrales e históricas propias del proceso pos-fordista que denotaron con una fuerte situación de degradación urbana en lo que fue en algún momento la ciudad central y reluciente. Dicha renovación presupone un desplazamiento paulatino por parte de una clase social pauperizada a raíz de la incursión de una clase social mediana y alta, la cual cuenta con poder económico y político para trasformar los espacios históricos degradados en lugares productivos económicamente mediante la implantación de usos nuevos o más intensivos en el sector, que ofertan espacios de producción económica dirigida a una población de consumo específica, aumentando la capacidad de acumulación de capital y posteriormente elevación en el precio del suelo urbano (Artasu, 2011).

Estas dinámicas socio/espaciales producen procesos de acomodación de los usos del suelo para ser aprovechados por el capital inmobiliario entre otros tipos de capital, agudizando la segregación socio espacial, que empieza a ser dirigida por algunos actores urbanos interesados en la recuperación y revalorización económica de estos sectores que en la lógica de la ciudad capitalista no generan plusvalías o captación de renta para el sector privado, llevando posteriormente a un proceso de Gentrificación (Williams, 1986).

Ahora bien, abordando desde un análisis a escala local, específicamente en la ciudad de Ibagué, de acuerdo a lo anterior, se puede inferir en que el sector céntrico e histórico de la capital tolimense parece obedecer a algunos aspectos característicos del proceso de renovación urbana especialmente entre la carrera primera y la carrera séptima por la calle once de la ciudad de Ibagué. Hasta este punto cabe preguntarnos si ¿El sector de las carreras primera a décima entre calles primera a quince del centro histórico de la ciudad de Ibagué, son espacios susceptibles al proceso de renovación urbana? 
Figura 1. Centro histórico de Ibagué

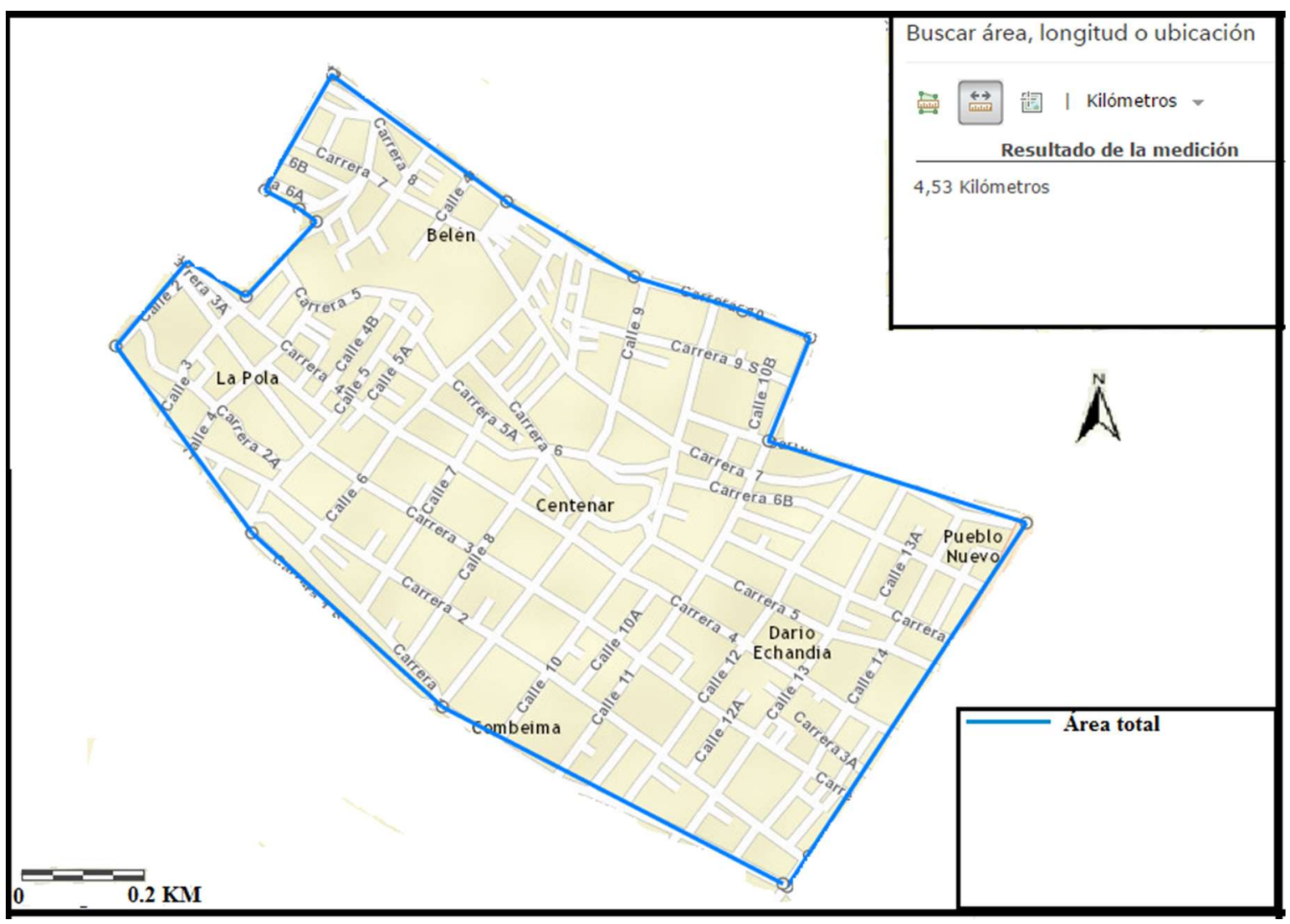

Fuente: Elaboración propia.

La renovación urbana como se mencionó anteriormente es un fenómeno urbano que consiste en la reproducción económica, social y cultural de los barrios centrales de las ciudades, ejecutada por una clase socioeconómica media o alta, cuyo objetivo es adaptar los centros urbanos deteriorados en potenciales espacios productivos a partir de la captación de renta y o plusvalía, generando, en su defecto, que los antiguos habitantes de estos centros desalojen paulatinamente dicho sector como consecuencia de la alta especulación del suelo que se manifiesta en el alza de servicios públicos entre otros factores de orden económico que afecta directamente esta capa social urbana (Slater, 2011; Abramo, 2016).

Históricamente en materia de análisis de este fenómeno urbano se ha escrito desde la mitad del siglo XX, para la fecha se puede destacar uno de los estudios más sobresalientes realizados en materia de renovación urbana en un caso histórico, pues en el año de 1964, la socióloga británica Ruth Glass identificó los elementos característicos de este fenómeno, cuando en su oficio como directora del Social Research at University College London, lideró algunos estudios que se enfocaron en analizar las causas y posibles consecuencias del arribo de grupos de clase media o elites sociales en barrios de clase obrera y populares. A partir de aquel momento, la socióloga marxista acuñó el neologismo de Gentry que se caracterizó como peyorativo a las clases socioeconómicas altas y medias que se emplazaron por aquel entonces en los centros populares de la ciudad de Londres, específicamente en el distrito de 
Islington, donde este proceso de emplazamiento social generó detrimento en la clase trabajadora quienes posteriormente fueron expulsados de sus lugares de origen (Slater, 2011, p. 1).

A raíz del importante aporte teórico generado por esta autora a principios de 1960, en los años posteriores, desde comienzos de los 70 y durante los 80 del siglo pasado, brotó del mundo anglosajón un sin número de estudios dedicados a la comprensión y trascendencia teórica de lo que fue en aquel entonces la "gentrificación" en las ciudades europeas y norte americanas. En este momento surge en la escena de los estudios urbanos el geógrafo escoses Neil Smith quien fue una de las figuras más destacadas en el ámbito del estudio urbano y exactamente en el de la "gentrificación", desde una postura marxista, Smith elaboró un importante análisis en materia de renovación de las ciudades norte americanas (Williams, 1986). Del mismo modo, en 1996 Neil Smith en su obra titulada: La nueva frontera Urbana. Ciudad revanchista y gentrificación ,hace hincapié en que la gentrificación es un proceso que genera el mejoramiento de las condiciones físicas y sociales de un espacio deteriorado, el cual, se convierte en un espacio atractivo para la inversión de capital por parte de agentes inmobiliarios o personas en condición de pequeños inversores quienes aprovechan la oferta de estos suelos que se presentan a un bajo costo, buscando de esta manera el máximo beneficio de producción y reproducción de capital fijo, a esta dinámica generadora de renta urbana Smith la ha denomina "Rent-gap", como un elemento a tener en cuenta en los análisis que se proyectan en materia de gentrificación de las ciudades del mundo y lo que concierne en la ocupación de nuevos habitantes de clase media.

Por otro lado, surgen los aportes teóricos del geógrafo canadiense David Ley, señaló que la gentrificación es un proceso de reconfiguración demográfica y económica de la cual, algunos grupos de clase media se beneficiaron a medida que encontraron en los centros de las ciudades nuevas formas de habitarlas a través de una trasformación arquitectónica y cultural que obedecía a una demanda de población joven, soltera y sin hijos, entre tanto, D. Ley infiere que a partir de lo se denominó como "Baby boom" en los años 70, se incrementaron el número de hijos en la clase obrera donde según el autor, la tasa de divorcio se triplico considerablemente en norte américa para mediados de los años 70 y principios de los 80 , generando un desplazamiento por parte de esta población hacia el centro histórico de la ciudad, donde sostenerse así mismo llegaba a ser más rentable, tal como lo señala a continuación:

Associated whit this growth in numbers has been a sharp reduction in household size. This is a product of several factors, including more plural lifestyles in an environment of changing opportunities. More women are entering the labor force; in Canada labor force participation increased from 37 percent of women in 1971 to 52 percent in 1982, whit similar figures reported for the U.S. More persons are remaining unmarried, and the divorce rate tripled in America between 1960 and 1975. The result has been an explosive growth of small households; indeed by 
1978 over one-half of an America households consisted of one person ${ }^{2}$ (Ley, 1986, p. 4).

Al mismo tiempo, aparece una serie de documentos que analizan la gentrificación desde el ámbito cultural evidentemente impregnado por conceptos posmodernos, es decir, en los espacios urbanos céntricos renovables hay un cambio sustancial en preferencias de consumo y vivienda, que convergen en nuevos gustos bohemios que caracterizan a los "gentrificadores" como actores cambiantes del paisaje urbano de un espacio central determinado. Por otro lado, el papel que juega la cultura de consumo abre el camino hacia una mejor comprensión del proceso de gentrificación y las dinámicas que se presentan a partir del consumo masificado en espacios degradados (Lucas, 2001).

Del mismo modo, Garry Robson y Tim Butler en su libro Coming to termswhit London: middle class communities in a global city (Butler, 2001) señalan partiendo desde el ejemplo de la ciudad Londinense, cómo el tipo de arquitectura clásico de estilo victoriano y bohemios, entre otros aspectos artísticos, son ofrecidos en espacios potencialmente gentrificables hacia un grupo de consumidores que ofertan y demandan un estilo de vida particular. Sin embargo, teniendo en cuenta el análisis anteriormente realizado, adoptamos el termino de Renovación urbana, único en la fidedigna forma de reconcentrar capital en los centros urbanos por parte de una clase política y económica que no se diferencia por neologismos o análisis antagónicos y estructuralistas que tratan de definir un problema que compete toda una base teórica que desde la historia se ha analizado cuidadosamente.

\section{QUINCE AÑOS DEL ACCIONAR POLÍTICO EN MATERIA DE RENOVACIÓN URBANA EN EL CENTRO HISTÓRICO URBANO DE LA CIUDAD DE IBAGUÉ}

Las políticas de planeación de las ciudades y lo que se desprende de ellas como es el crecimiento de la mancha urbana o algunas modificaciones de las mismas están reguladas principalmente por el Estado, único ente regulador de dicho metabolismo urbano y gendarme de la vida urbana a mediano y largo plazo. Sin embargo, a finales del siglo XX y comienzos del presente siglo, América latina comenzó a vivir una fuerte dinámica de inversión de capital inmobiliario en sus ciudades, esta situación paulatinamente llevó a los gobiernos de estos países a implementar políticas de organización de sus territorios urbanos, preparándolos para el boom de capital que se vaticinaba y sus inevitables daños colaterales que acarrarían al

\footnotetext{
${ }^{2}$ Traducción: “Asociado este crecimiento en el número de pobladores nuevos ha sido una fuerte reducción en el tamaño del hogar. Este es un producto de varios factores, como el estilo de vida más plural en un ambiente de oportunidades cambiantes. Muchas mujeres están entrando en la fuerza de trabajo; en Canadá la tasa de actividad aumentó de 37 por ciento de las mujeres en 1971 al 52 por ciento en 1982, una taza de figuras similares reportados para los EE.UU. Más personas se están quedando sin casar, y la tasa de divorcios se triplicó en Estados Unidos entre 1960 y 1975. El resultado ha sido un crecimiento explosivo hogares pequeños; de hecho, en 1978 más de la mitad de unos hogares en América del norte consistía de una persona por vivienda”.
} 
paradigma económico que arremetía la sociedad Latino americana a finales de los $90 \mathrm{y}$ comienzos del 2000. (Matinez, 2011).

Frente a este panorama, no solo fueron las políticas que se modificaron para el boom en la inversión urbana, también y aún más importante, fueron las concepciones de organización urbana que se entretejieron con las estratégicas reformas neoliberales que actuaban ya en aquel momento en el marco de la desregularización económica y la liberalización del suelo urbano, una apertura que llevaría a los organismos de planeación locales y departamentales a forjar draconianamente una hoja de ruta para lo que sería la ciudad del siglo XXI. De este modo, la apertura del mercado de la tierra urbana generó grandes inversiones no solo de empresas inmobiliarias que tienen su interés puesto en las ciudades y sus deteriorados centros urbanos sino de grandes y poderosos grupos familiares, llevando a los gobiernos a confiar más en la inversión privada que en la misma inversión pública. En este sentido, (Mattos, 2001) señala que:

La desregulación se propuso y logró eliminar ciertas disposiciones que entorpecían las decisiones de los empresarios inmobiliarios y de las familias, cuyas preferencias y estrategias específicas juegan un papel fundamental en el proceso social que modela la ciudad [...] Con ello quedó libre el camino para que la maximización de la plusvalía urbana se consolidase como el criterio urbanístico predominante, asumiendo una fuerza capaz de desbordar muchas de las regulaciones están aún vigentes. Como resultado de ello, a partir de allí buena parte de las principales intervenciones urbanas nuevas han emanado de iniciativas privadas aisladas, decididas en función de la rentabilidad esperada para cada una de ellas, con lo que ha terminado por afirmarse un proceso fragmentario de construcción de ciudad (Mattos, 2001, p. 24).

Del mismo modo, a mediados de 1996 en la segunda conferencia internacional sobre asentamientos humanos (HABITAT II) realizado por la ONU en Estambul Turquía, se hizo hincapié en que el sector privado debe engranarse necesariamente con las políticas de planeación urbana de los estados latinoamericanos, fomentando desde aquel entonces, el discurso estético y propositivamente político de la vida privada en la planeación denominado la "nueva ética" urbana que hacia su aparición como un espectro de la modernidad urbana en la súper-estructura de la sociedad y sus eventuales modificaciones (Schteingart, 2007, pág. 719).

Los centros históricos o tradicionales ${ }^{3}$ no escapaban por supuesto a aquellas virulentas reformas que se manifestaron desde finales del siglo XX y comienzos del siglo XXI, era allí, específicamente en lo viejo de la ciudad, que se deparaba un grueso proyecto renovador en la infraestructura física y social de nuestros centros sin importar la conservación de aquellos monumentos que habían soportado el tiempo que los condenaba a la obsolescencia y la indiferencia administrativa.

${ }^{3}$ Centro tradicional es aquel centro que se configura urbanísticamente, que no tiene una espacialidad determinada y que 
En Colombia, a partir de la Ley 338 de 1997, se dictaminó que todas las ciudades deberían contar con un P.O.T. para la verificación y posterior cumplimiento de la planeación urbana a corto, mediano y largo plazo. Para el Ministerio de Ambiente, Vivienda y Desarrollo Territorial - MAVDT, 20013:5) el P.O.T. es:

Un instrumento técnico y normativo de planeación y gestión de largo plazo; es el conjunto de acciones y políticas, administrativas y de planeación física, que orientarán el desarrollo del territorio municipal por los próximos años y que regularán la utilización, ocupación y transformación del espacio físico urbano y rural. Un P.O.T. es en esencia, el pacto social de una población con su territorio (Ministerio de Ambiente, 2003).

Por otro lado, para la ciudad de Ibagué, a partir del año 2000, se ejecutó el Plan de Ordenamiento Territorial. Esta matriz de planeación y ejecución de las políticas urbanas merece un análisis detallado en lo que respecta a la renovación y la noción de centro histórico que el mismo documento tiene, pero fortalece dicha noción de centro histórico como elemento educativo e identitario para la ciudadanía ibaguereña, pues a partir de estos dos conceptos renovación y centro histórico, podremos analizar las políticas que han determinado el accionar en el centro de Ibagué y su evidente revitalización como un espacio para la captación de plusvalías del suelo urbano.

\section{¿QUÉ ES LA RENOVACIÓN URBANA SEGÚN EL P.O.T. DE IBAGUÉ?}

En el Plan de Ordenamiento Territorial encontramos en que la renovación urbana es ante todo un tratamiento urbanístico, es decir, una clasificación designada por planeación para ejecutar acciones de mejoras en la infraestructura física y social de cualquier zona de la ciudad de Ibagué. La renovación urbana, según el artículo 164, parte de unos principios que se desarrollan trasversalmente, puesto que para renovar según el P.O.T., se necesita seguir unos pasos de desarrollo, conservación y finalmente renovación del inmueble o el activo que se pretende renovar. En este sentido, la renovación según el P.O.T. se ejecuta como una:

implementación a través de planes parciales y mecanismos de participación que preverán la habilitación y el mejoramiento de las infraestructuras, equipamientos y espacio público necesario para atender nuevas densidades y usos del suelo asignados a la zona, garantizando la planeación integra por sectores posibilitando igualmente las unidades de actuación urbanística (P.O.T.). 
Esta misma concepción de renovación urbana también se puede apreciar en el artículo 190 y 195 del Plan de Ordenamiento Territorial ${ }^{4}$. Dentro de la misma normatividad expresada por el P.O.T. en materia de renovación y entendiendo por supuesto, que dicha renovación es ante todo un tratamiento urbanístico que promueve el mejoramiento integral de la infraestructura física de toda la ciudad. En el artículo 199 encontramos la normatividad para la intervención en los inmuebles declarados como patrimonio histórico de la ciudad. Ahora bien, esta intervención, según el Plan de Ordenamiento Territorial, son aquellos procesos de renovación que buscan actualizar funcionalmente el inmueble con relación a un uso específicamente asignado es decir (revitalizarlos) a partir de la asignación del uso del suelo, así mismo se renueva el inmueble ya sea para producción turística, comercial o política en algunos casos ${ }^{5}$.

Teniendo en cuenta lo anterior, Rojas (2011, p. 12) infiere que "el gobierno puede también intervenir regulando el uso de los bienes patrimoniales para evitar su destrucción o daño por mal uso". Esto, según el P.O.T. atiende a las necesidades de consolidar un bien público que hace parte de la memoria de toda la ciudad, sin embargo, más adelante veremos como la concepción de bien público emitido desde la renovación de inmuebles antiguos se ha diluido, pues el centro, como veremos a continuación, evidentemente se ha renovado, pero no con un propósito social e identitario del valor histórico impregnado en la cal y el cemento de aquellos edificios y calles que guardan una historia poco conocida. Por otro lado, para el año 2002 la administración local elaboró y ejecutó a partir de la Ley 136 de 1994 y de acuerdo a lo dispuesto en la ley 388 de 1997 el acuerdo 009 del 2002, donde se adoptó la normatividad general de los usos, construcciones y urbanizaciones en el municipio. Este documento infiere en que la renovación es ante todo un uso establecido afirmando que:

Son planes de renovación urbana aquellos dirigidos a introducir modificaciones sustanciales al uso de la tierra y las construcciones, para detener los procesos de deterioro físico y ambiental de los centros urbanos, a fin de lograr, entre otros, el mejoramiento del nivel de vida de los moradores de las áreas de renovación, el aprovechamiento intensivo de la infraestructura establecida de servicios, la densificación racional de áreas para vivienda y servicios, la descongestión del tráfico urbano o la conveniente rehabilitación de los bienes históricos y culturales, todo con miras a una utilización más eficiente de los inmuebles urbanos y con mayor beneficio para la comunidad (Ibagué, 2008, p. 72).

Curiosamente el Acuerdo 009 del 2002, define una política más explícita de lo que fue en su momento renovar el centro histórico de la capital tolimense, naturalmente, este Acuerdo se

\footnotetext{
${ }^{4}$ En este sentido, el P.O.T. afirma que la renovación urbana "promueve la utilización de instrumentos de carácter asociativo a través de planes parciales, de manera que se habilita la utilización de mayores aprovechamientos y toda la gama de incentivos derivados de la utilización de esta figura de acuerdo con la ley 388 de 1997. Igualmente permite desarrollos predio a predio a partir de un bajo aprovechamiento, correspondiente al medio existente en la zona hasta el momento de adopción del plan parcial para la misma".

${ }^{5}$ En algunos casos encontramos que algunos inmuebles con un alto contenido histórico son utilizados por algunas secretarias de las administraciones como la alcaldía entre otras entidades del poder público.
} 
ejecutó porque se avecinaron cambios sustanciales en el entramado urbano del centro histórico de la ciudad de Ibagué, era necesario, según el gobierno local, dejar claras las políticas públicas que se verían ejecutadas en la zona céntrica e histórica, pues fue un proyecto de intervención económica publica a partir de sus mismas políticas la que dieron paso posteriormente a un cambio rotundo del uso del suelo y las eminentes modificaciones microeconómicas que tendría nuestro centro en años posteriores en manos del capital privado.

Esta alteración de la geografía urbana del centro a partir de las mencionadas políticas de intervención pública y privada traerían consigo, como lo veremos a continuación, colosales trasformaciones en la infraestructura del sector, del mismo modo, múltiples formas de apropiar y vivir el espacio de acuerdo a las demandas globales que en aquel momento recaían sobre nuestras ciudades latinoamericanas y especialmente sus centros poco "rentables" para la época.

\section{DESARROLLO DE PROYECTOS DE RENOVACIÓN URBANA: PEATONALIZACIÓN DE LA CARRERA TERCERA Y APERTURA DE UN CENTRO HISTÓRICO Y URBANO MÁS RENTABLE}

En la ciudad de Ibagué a partir del año 2000, es decir, en plena ejecución del Plan de Ordenamiento Territorial, se implementó una serie de proyectos que serían materializados desde el año 2003 como fue el caso de la peatonalización de la carrera tercera en el centro de la ciudad. Según (Ramirez, 2014), el problema de la administración central de la época fue que la ciudad presentaba problemas en lo que respecta a su espacio público, es decir, saturaciones e inconvenientes en la movilidad del centro urbano, dichos problemas comenzaron a tener solución a partir del Decreto 500 del 2002 que materializaba la sentencia popular del Tribunal Administrativo del Tolima del año 2000, donde el Tribunal ordenó directamente a la administración local poner en marcha un plan parcial de renovación y modificación del espacio público del centro de la ciudad. En este sentido, el plan de peatonalizar la tercera, solucionaría los problemas de movilidad causada por los vendedores ambulantes, del mismo modo, este proyecto de vanguardia cambiaria positivamente el paisaje urbanístico de todo el entramado histórico espacial del centro de la ciudad ibaguereña (Ramirez, 2014). Por otro lado, los medios de comunicación de la fecha no eran ajenos de la incertidumbre que se manifestaba en todos los ciudadanos de Ibagué y la manifestación de un proyecto urbano que para la época era prometedor. El periódico el Tiempo el 6 de agosto del 2003, emitió un artículo refiriéndose a la peatonalización de la "Calle Bonita" en el que infería lo siguiente:

\footnotetext{
${ }^{6}$ Calle bonita es un neologismo adoptado por la población ibaguereña para referirse a la carrera 3ra después de su peatonalización
} 
El proyecto que mejorará las condiciones ambientales y paisajísticas de esta importante vía del cetro de la ciudad, será ejecutado en tres fases. Hoy comienza la primera parte, por lo que se cerrará el paso vehicular entre las calles 10 y 12 sobre la carrera tercera. La segunda fase comprende las calles 12 y 14 y la tercera, de la calle 14 a la 15. Según voceros de la alcaldía de Ibagué, la peatonalización de la carrera tercera debe ser un hecho antes de finalizar el presente año (Tiempo N. V.).

\section{Figura 2. Perspectiva de la peatonalización de la carrera tercera}

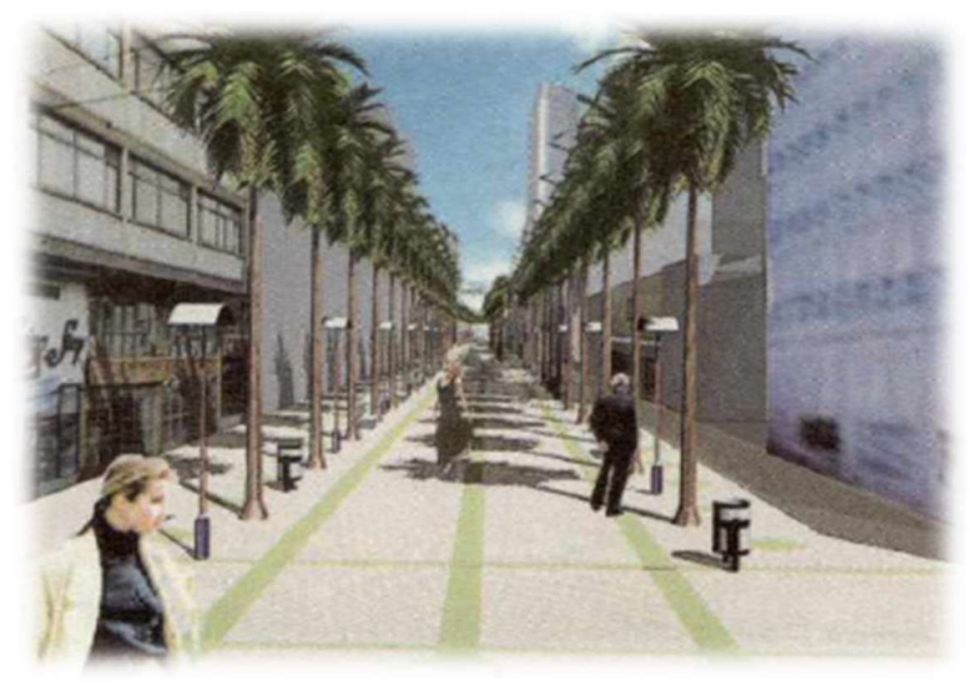

Fuente: (del periódico Tolima 7 días 2003 pág. 28).

De acuerdo con lo emitido en el 2003 por el periódico del Tiempo, la mejora en las escenarios urbanos como lo fue en materia ambiental y paisajística, obedecía a la nueva estética de ciudad moderna, una avalancha de ideas transformadoras que harían de lo antiguo una plataforma para captar capital a través de la cultura de consumo, pues, como se evidencio después de la peatonalización de la "Calle Bonita" a finales y comienzos del año 20047, el objetivo no era edificar un espacio ameno para los ibaguereños, donde estos pudieran recrear o "hacer amigos", por el contrario, fue un proyecto que capitalizó la llegada de los centros comerciales a la carrera tercera, convirtiéndola así, "en un centro comercial a cielo abierto" (Ramírez, 2014, p. 66).

\footnotetext{
${ }^{7}$ Fueron varios tramos los que se fueron peatonalizando, lo que permitió a la ciudad disfrutar de dicho proyecto desde mediados del 2003 y comienzos del 2004
} 
Fotografía 1. Carrera tercera. Año 2000

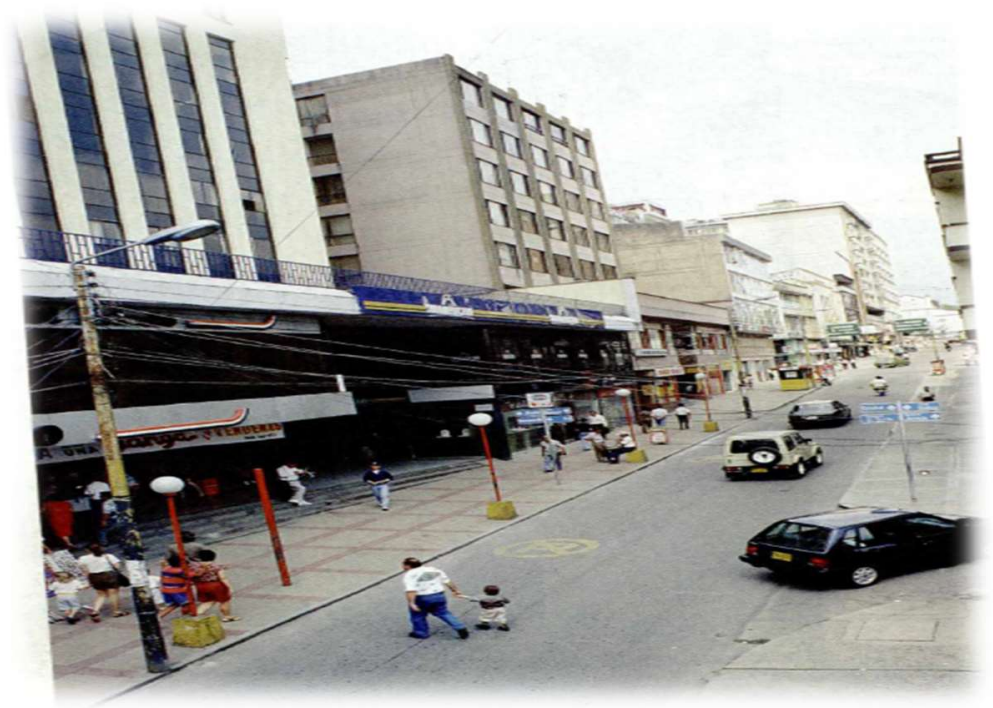

Autor: Pijao Editores (2000).

Fotografía 2. Carrera tercera. Año 2015

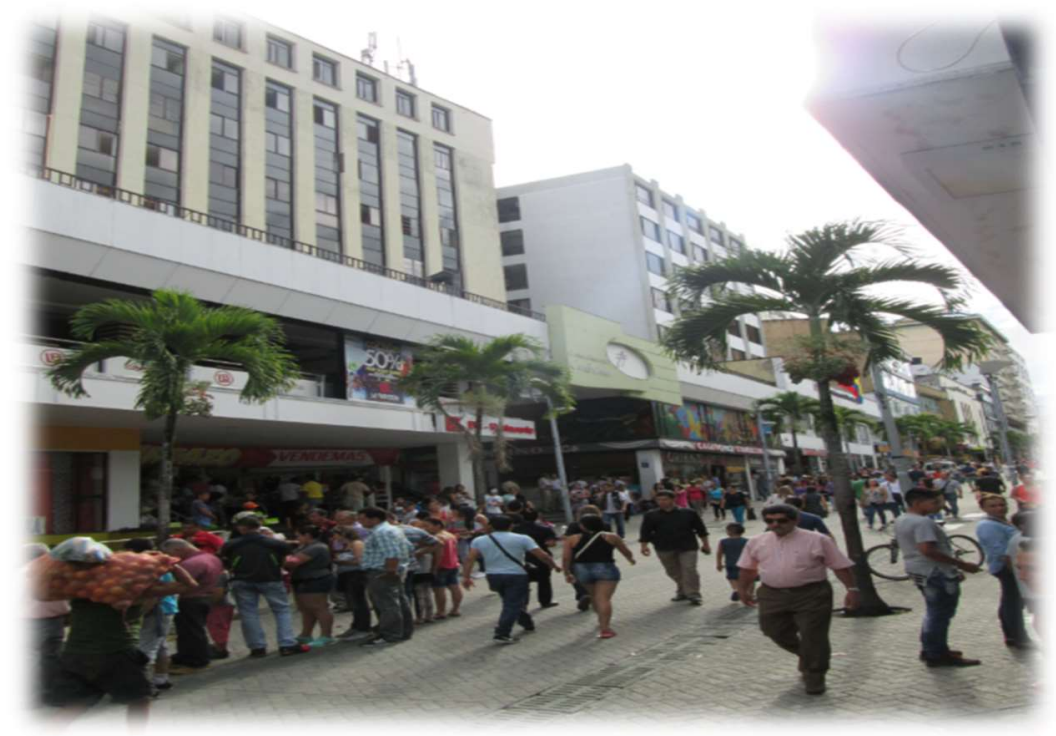

Autor: Julián Escobar (2015).

Un archivo del periódico El Tiempo titulado "Peatones en la vía", escrito el 1 de noviembre del 2002, hacia un pequeño análisis del día sin carro del 30 de octubre del mismo año, donde se pudo apreciar que, aun sin automóviles privados y solo automóviles prestadores de servicio público, la carrera tercera era un total caos derivado del congestionamiento tanto de transeúntes como de los autos que transitaban en la vía, ante este panorama, el periódico entrevistó al arquitecto y director de la recién abierta gestora urbana Noel Alejandro Gómez, quien le afirmo al periódico lo siguiente: 
La peatonalización de la tercera se dará inicialmente desde la calle 14 hasta la 11, con la posibilidad de que los vehículos puedan circular por dichas calles y, además, habrá acceso controlado para las personas que cargan y descargan y permisos especiales, en zonas demarcadas y restringidas, para quienes habitan el sector. Para este proyecto se vestirá la carrera con un moderno mobiliario urbano que consta de lámparas, casetas para revistas, bancas y un piso adoquinado, entre otras cosas, para que las personas que la recorran disfruten del espacio público. Queremos rescatar el paseo de vitrinas, la recreación y la lúdica en las plazoletas y potencializar la oferta comercial del sector. Se trata de armonizar el eje comercial con el cultural de la 10 y la 11, que contiene al Teatro Tolima y a la biblioteca Darío Echandía como principales exponentes, dijo Noel Gómez.” (Tiempo, 2002).

Fotografía 3. Carrera tercera con calle 14. Año 2002

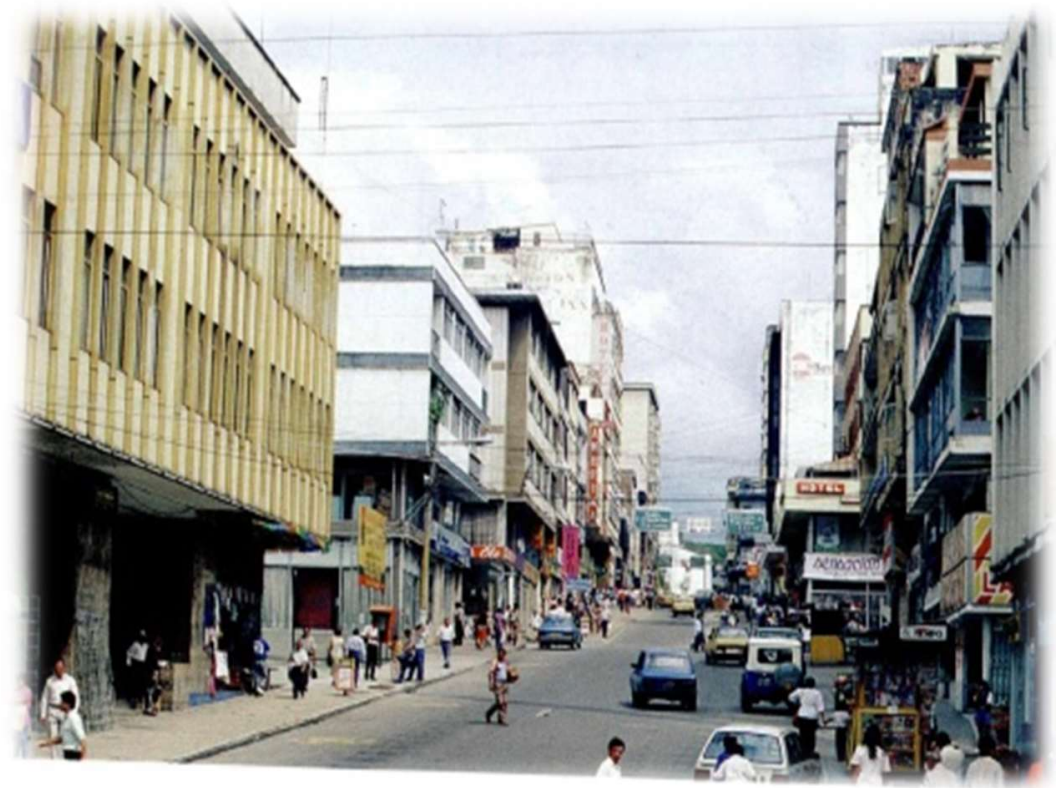

Fuente: Pijao Editores (2002). 


\section{Fotografía 4. Carrera tercera con calle 14. Año 2015}

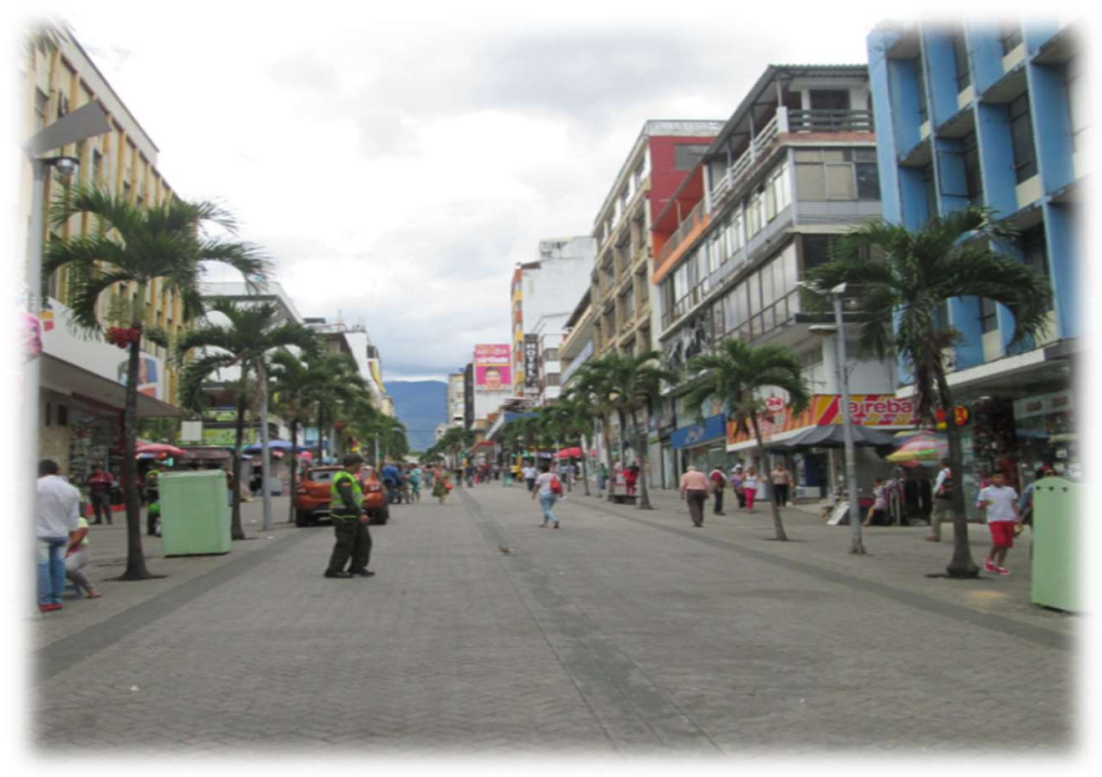

Autor: Julián Escobar (2015).

La experiencia de la peatonalización de la carrera tercera, ha suscitado varias preguntas que se mantienen latentes desde sus días de modernización como la calle de los peatones de Ibagué, una de ellas es si ¿este proyecto ha consolidado a la apropiación del espacio público de la carrera tercera y en especial, del centro de Ibagué? O por el contrario, ha sido una manifestación de la apertura del centro histórico hacia la captación a gran escala de capital, privando muchas veces, la producción espacial de las mismas personas que viven y perciben este centro como un tugurio de mercancías como un espacio no vivido en vez de un centro rico en historias e identidades que se refrendan en la forma de crear espacios sociales y habitables fuera de la concepción draconiana y hegemónica y todos los problemas que han derivado de este proyecto de renovación del centro histórico de Ibagué.

\section{RENOVACIÓN Y OLVIDO: EL PARQUE DE LA MÚSICA, UN CENTRO QUE SE MUEVE AL SON DE LA MODERNIDAD}

El Parque de la Música es otro de los iconos más representativos del centro histórico de la ciudad en su etapa de renovación y revitalización de este importante sector. Este parque está ubicado hacia el costado sur occidental del centro de la ciudad, circundante al colosal y antiguo edificio el salón Alberto de Castilla fundado en $1902^{8}$, una obra maestra que se fue convirtiendo a través del tiempo en el símbolo de la cultura de la música y el templo de los

\footnotetext{
${ }^{8}$ Información obtenida de: http://www.colombiatravelguide.net/The Conservatorio del Tolima (photo, below) isargua bly Colombia's mes important music school. It was founded in 1906 and was first director by maestro Alberto Castilla, whose name the exterior of building now bears
} 
artistas tolimenses que se han preparado en este mismo edificio, pues en 1906, se fundó el Conservatorio de la Música, única universidad de músicos en el país.

El Parque de la Música, es un ejemplo entre la dialéctica de lo viejo y lo nuevo, del destruir para poder crear, del poder renovar para ser olvidado, es un proyecto que en este breve análisis ha materializado mucho de la cultura tolimense pero que está condenado a disolverse en el aire. El Parque de la Música fue fundado en el año 2008, un año después de haberse proyectado como el más joven de los parques y el más representativo hasta en aquel momento de la cultura tolimense. Fue diseñado por la arquitecta Carolina Perea vinculada a CAMACOL regional Tolima, quien decidió nombrar el proyecto SOL (Parque de la Música) en conmemoración a la quinta nota musical en la escala diatónica del do mayor y la nota más representativa del son musical en la notación latina.

Para la fecha, el proyecto era lo suficientemente importante para las administraciones local y regional, pues el haber invertido aproximadamente 4 mil millones de pesos en la ejecución de este proyecto, llevaría a los funcionarios de la época a plasmarse en los hitos de la historia arquitectónica y cultural como los pioneros en construir para renovar todo un sector céntrico e histórico que por aquel entonces estaba en decadencia.

El Parque de la Música desde sus comienzos, fue un sitio de atracción en potencia, no por el contenido implícito de la música que llevaba por sí solo, más bien, fue la novedosa fuente de agua con luces y los rudimentarios hombrecillos con instrumentos musicales a escala humana que hacían del sector del centro un atractivo turístico donde las familias eran las primeras en disfrutar aquella manifestación de la modernidad en un centro un poco olvidado. Sin embargo, este proyecto no duraría mucho como se había pensado, con el paso de los días, de los meses y el poderío del sol y el agua, se fue desvaneciendo lo que alguna vez fue llamativo, lo moderno, lo atractivo.

El parque fue perdiendo su color, las fuentes de agua ya no servían y los hombrecillos a escala humana hechos de metal se estaban pudriendo al compás del agua y el vituperio radiante del sol que cayó sobre ellos, el Parque se fue despoblando paulatinamente como lo hacían las hojas de aquellos árboles que acompañaban dicho parque; el cambio de visitantes fue lo más representativo del cólera de este monumento a la música, pues ya no eran familias las que visitaban este lugar, por el contrario, eran habitantes de la calle y jóvenes consumidores de psicotrópicos los que se apropiaron de este espacio.

El Parque de la Música como proyecto de renovación del sector céntrico ayudó a revitalizarlo, propuso nuevas formas de apropiación y construcción del espacio a través de componentes socio culturales que estaban íntimamente imbricados con la historia musical del municipio y porque no, del departamento. 
Fotografía 5. Parque de la Música. Año 2009

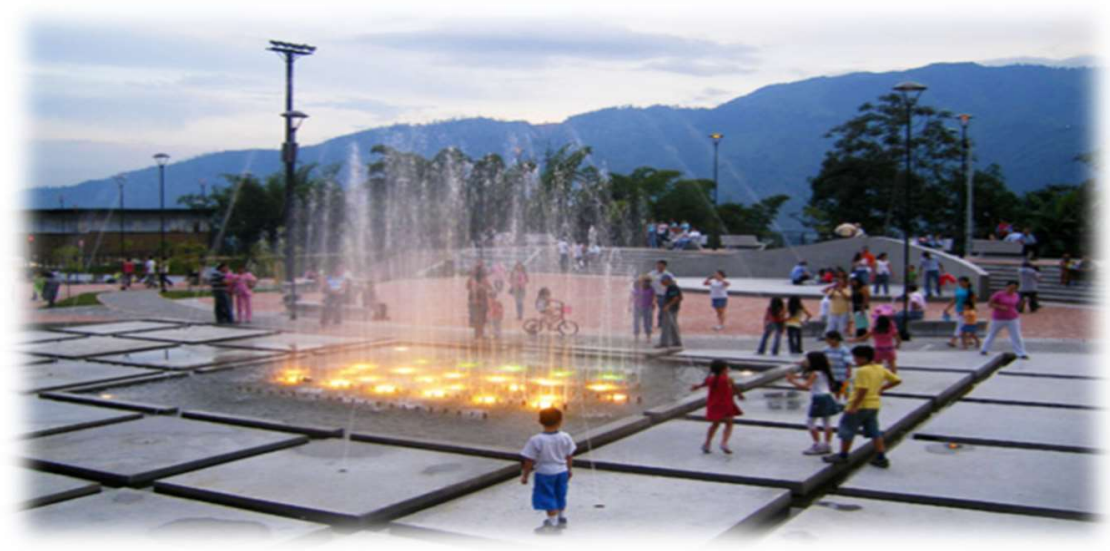

Fuente: $<$ http://www.colombiatravelguide.net/ibague.html $>$.

Fotografía 6. Parque de la Música. Año 2015

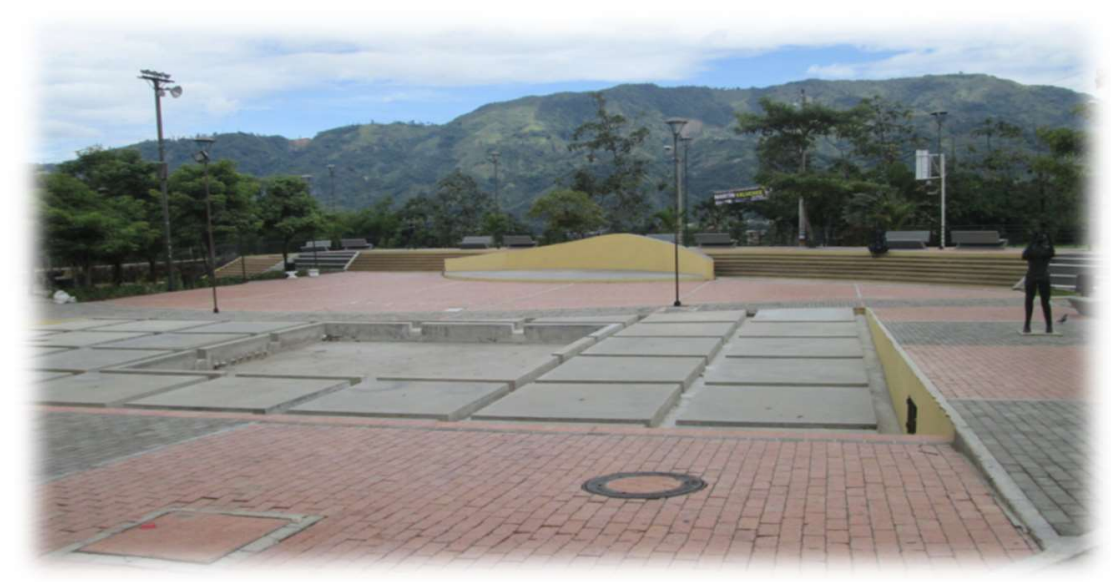

Autor: Julián Escobar (noviembre de 2015).

Para el año 2012, una extraña noticia daba un respiro de esperanza para aquel parque que una vez fue el atractivo de todos los ibaguereños en su paso por el centro histórico de la ciudad. El periódico el Nuevo Día, publicaba el 28 de diciembre del 2012 un informe de la UNESCO que señalaba en que el Parque de la Música de la ciudad de Ibagué era considerado como patrimonio de la Humanidad, para el mismo redactor del periódico, esta noticia se hacía un poco extraña teniendo en cuenta el estado deplorable de dicho lugar, pues en la cabeza del informe se señalaba que, "basada en su novedosa propuesta estética, que consta de una fuente sin varillas ni luces y sillas con puntas desvencijadas, entre otros elementos, la Unesco declaró al Parque de la Música como Patrimonio Material de la Humanidad" (Periódico, 2012).

Ante este panorama, a partir de la resolución 225 del 2012, el Concejo Municipal de Ibagué inexplicablemente decide no aprobar la renovación del Parque de la Música, pues, según 
dicho concejo le informó al periódico el Nuevo Día que; "El cambio que ha sufrido este parque lo ha hecho ver incluso más atractivo que cuando fue inaugurado, por cuanto pedimos no efectuar instalaciones ni reparaciones de cualquier índole en los próximos 300 años" (Periódico, 2012).Tristemente, el concejo decidió que el parque se veía mucho mejor deteriorado, arrastrándolo aún más al olvido de la ciudad moderna, las políticas, que en su efecto deberían servir para cuidar y consolidar un patrimonio humano ubicado en el centro histórico de la ciudad, son obsoletas, tan obsoletas como los mecanismos de control administrativos que han pasado durante los 15 años de apertura de un centro histórico casi olvidado.

Es precisamente esta dialéctica, de renovar para olvidar la que juega un rol importante en las políticas de renovación, pues deja la sensación que cada administración maneja una concepción de renovación a través de las políticas que pareciera dejar al olvido lo que le pertenece por derecho a la ciudad. Sin embargo, y ante esta dolorosa situación, el no interceder por un cambio necesario en la dinámica espacial del Parque de la Música a partir de los 7 años de ejecución de dicho proyecto no impediría de que el centro se ofertara de manera espontánea para todos los habitantes de la ciudad, aunque el parque quedara por fuera del proyecto de renovación de la ciudad, este mismo problema del poder local generaría otro tipo de apertura que traería consigo renovación no solo arquitectónica sino cultural y urbanística, una trasformación que trascendió de la forma de concebir el centro histórico de la ciudad, no por su cualidad como contenedor de historias plasmadas en sus calles y edificios, sino por el capital inmobiliario que hizo su aparición como espectro de lo moderno

\section{PANÓPTICO, UNA ESTRUCTURA QUE SE HA DISUELTO EN EL AIRE}

Uno de los monumentos más representativos del proyecto de renovación urbana es el del Panóptico de Ibagué construido en 1906, fue en su momento una cárcel y tugurio de inequidades y violaciones de derechos humanos para convertirse a partir del siglo XXI en un espacio de atractivo juvenil y consumos poco tradicionales, este presente enciso dedicara un pequeño análisis a su proceso de renovación y el poderío que ha generado en la revitalización del centro histórico de la ciudad Ibagué.

Para finales del siglo XX, ya cuando este monumento se veía desplomado y olvidado sin ser rescatado por su riqueza histórica y patrimonial, brota sin esperarse una buena noticia sobre los cimientos de este edificio antiguo que posibilitaba el volver a mirar dicha edificación con ojos de productividad, es decir, poder vislumbrar aquella estructura tan reluciente es importante como lo fue en algún momento en sus días iniciales.

En el año de 1998 es decir, 108 años después de la edificación del antigua construcción, se declara al panóptico un bien de interés cultural de carácter nacional (Periodico el Nuevo Día, 2003), esto traería consigo organizar el aparato político y económico de todo el departamento, pues a partir de esta noticia se establecieron fuerzas de poder entre la alcaldía de Ibagué y la gobernación del Tolima, ya que era necesario un grueso presupuesto 
económico que determinaría la renovación y revitalización del panóptico y su posible regreso a la vida urbana. En este sentido, el periódico Tolima 7 días señaló lo siguiente:

Cuando el Gobernador del Tolima, Guillermo Alfonso Jaramillo Martínez presenta la propuesta al Gobierno Nacional. El 27 de diciembre de 2001, se realiza la firma del convenio entre la Gobernación del Tolima y el Ministerio de la Cultura mejorar en aspectos comercial, habitacional y cultural. Por ejemplo, en el lugar donde nace la vía, específicamente en el Panóptico, la Gobernación del Tolima, el Viceministerio de por valor de 5.000 millones de pesos para la restauración del Panóptico de Ibagué (Periódico El Nuevo Día, 2003, p. 56)

\section{Fotografía 7. Perspectivas del proyecto de renovación en el panóptico}

\section{Centro de paz y cultura}

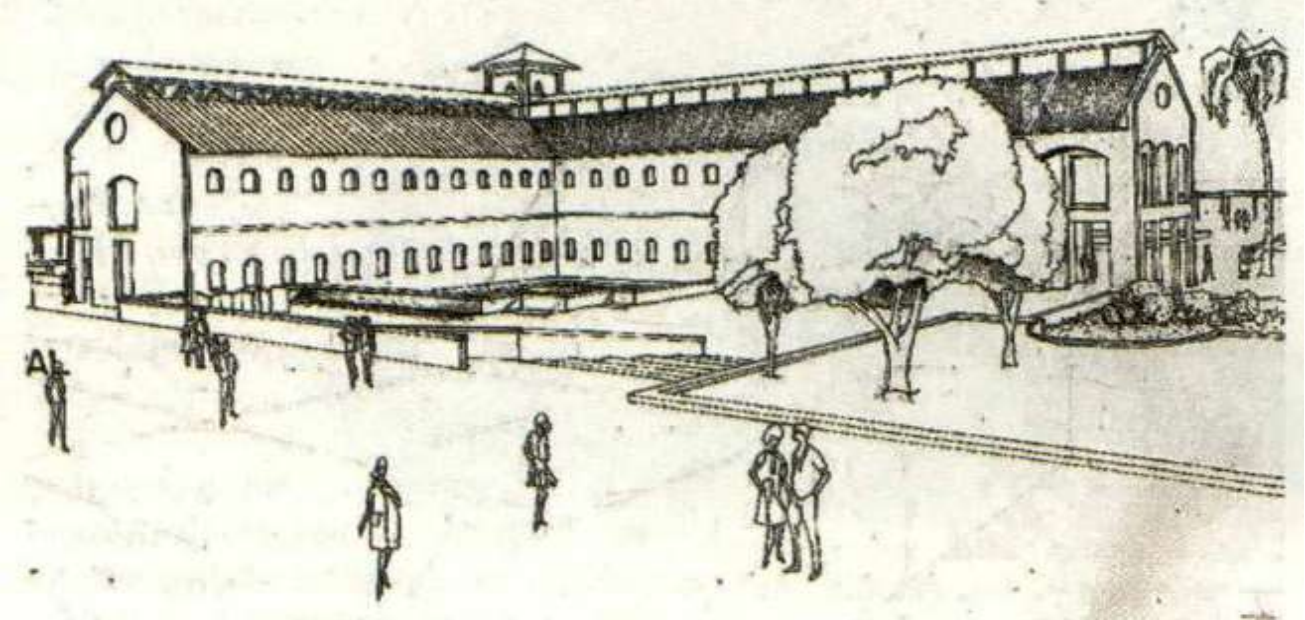

El Panóptico será un lugar de encuentro ciudadano y dinamizador de la economía local.

Fuente: Periódico El Tolima 7 Días, 2003, p. 56 página 56.

El objetivo de renovar el panóptico como un commodity a escala local desde el entramado de las políticas públicas, obedecía a las demandas de una economía sostenible basada en aspectos turísticos por medio de una cultura e historia colectiva, en este sentido, según (Rojas, 2011) los gobiernos locales de los países latinoamericanos actúan preservando sus viejos patrimonios arquitectónicos bajo la necesidad de captar renta de los usos de aquellos bienes obsoletos a partir de la intervención en la obsolescencia física y económica de estos inmuebles (Rojas, 2011, p. 4). Dicho lo anterior, se pueden apreciar las verdaderas intenciones de la renovación del panóptico, pues en ella impera fuertemente una concepción económica, en el sentido de devolverle al edificio viejo y obsoleto una vida productiva para 
potencializar económicamente el centro histórico de la ciudad de Ibagué; sin embargo, llegarían los altibajos del proyecto de renovación de este claustro de historias.

Para el 7 de abril del 2008, el periódico El Tiempo, publicó un artículo titulado "Antigua cárcel penitenciaria se convertirá en museo de los derechos humanos", en esta publicación, se hizo hincapié en las singularidades y aspectos positivos del panóptico de Ibagué y su importancia en la historia cultural que tiene este colosal inmueble en el imaginario de espacio público ibaguereño. A partir del año 2004, según el informe que se presentó en el artículo del periódico ya nombrado, Ibagué fue declarada "la capital andina de los derechos humanos y la paz por el Parlamento Andino" (Tiempo P. e., 2008) esto llevaría a la administración local a tomarse el espacio donde se vulneraron alguna vez los derechos humanos para poder construir paulatinamente espacios de esperanza que determinara la concurrencia masiva por parte de los ciudadanos locales y regionales en el centro histórico de la ciudad, así lo señaló el periódico el Tiempo:

El Panóptico busca ser el elemento principal de un corredor cultural del que hacen parte también el Teatro Tolima, el Museo Álvaro Mutis, la Biblioteca Darío Echandía, la Concha Acústica, la Plaza de Bolívar, la Casa Teatro, el Museo de Artes, el Parque Murillo Toro, el Cerro Pan de Azúcar, la Biblioteca Soledad Rengifo, la Plaza de los Artesanos, el Parque Botánico San Jorge, la Facultad de Artes, y el Parque de la Música, entre otros. (Tiempo P. e., 2008).

La cita anterior permite comprender que aquel centro es un corredor cultural, donde se hace imperativo renovarlo con el objetivo de fortalecer la identidad urbana de los ibaguereños, frente a las demandas de ocio que se ejercía por aquel momento en el centro histórico de la ciudad ibaguereña.

Para el 27 de junio del 2013, el periódico El Nuevo Día, en un artículo titulad "Panóptico no logro su pacto y cumplimiento, La acción popular lo que pretende es que se ordene la terminación de la renovación arquitectónica del Panóptico de Ibagué" critica de manera contundente, la negligencia de los gobiernos de turno por no accionar el presupuesto destinado para la remodelación del panóptico y en su efecto, de la zona centro de Ibagué. Dentro del mismo artículo, se entrevista al ex personero de la ciudad Isaac Vargas quien de manera sucinta señalo lo siguiente cuando se refería a la deplorable situación que sufría el Panóptico para el año 2013:

El Departamento que fue el responsable del contrato, lo que hizo, al notar el incumplimiento, fue liquidar el 30 de mayo de 2007 el convenio suscrito entre el consorcio de Ingenieros y Arquitectos del Tolima y la Gobernación. En ese mismo proceso, la aseguradora FUV demanda a través de acción de nulidad y restablecimiento del derecho, las resoluciones mencionadas, que decretaron el 
incumplimiento de las obras, con el fin de que se les exonere de pagar la póliza”. En tanto la acción popular va dirigida contra la Nación, el Ministerio de Cultura, la Gobernación del Tolima, el Municipio de Ibagué y otros, para defensa del patrimonio público y garantizar la ejecución de la obra (Briñez, 2008).

\section{Fotografía 8. Inicios del proyecto de renovación del Panóptico de Ibagué. Año 2008}

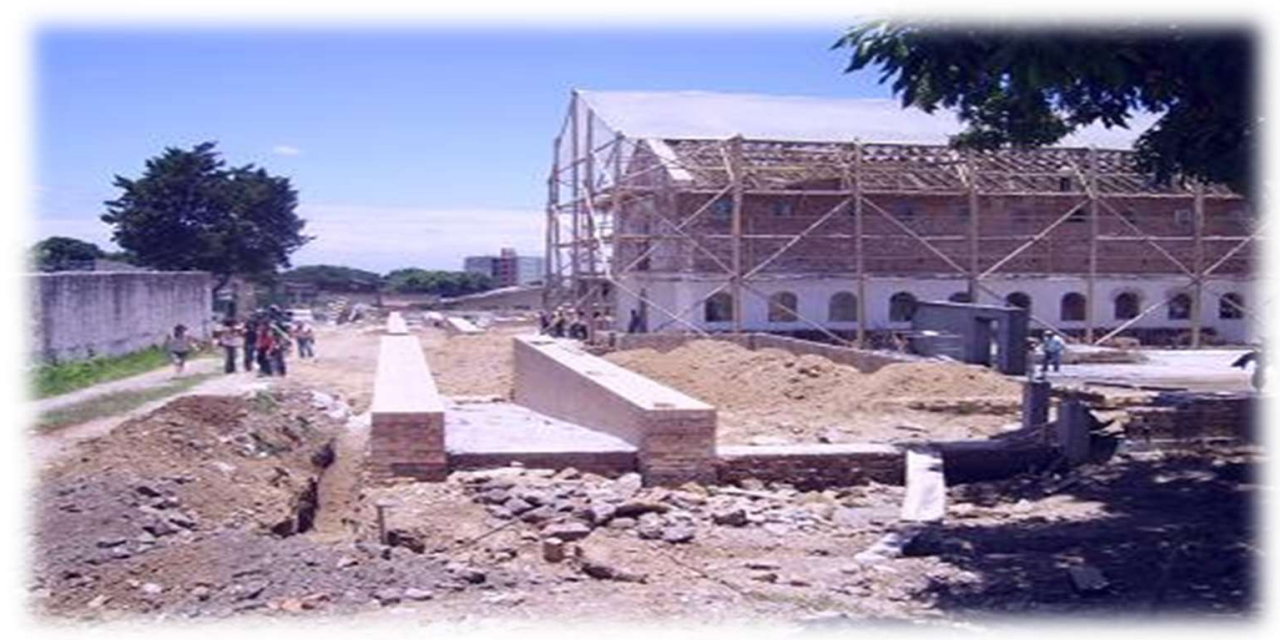

Fuente: Periódico digital Unilbagué (5 de octubre del 2010).

Con el llamado de atención de algunas entidades regionales departamentales, el Panóptico retomo las obras de renovación hasta ser concluidas a principios del año 2015. Pasaron aproximadamente 15 años de procesos políticos y desfalcos económicos para que este antiguo edificio se pudiera renovar, sin embargo, su remodelación solo se ejecutó en la parte exterior de esta estructura. Su interior, aún permanece aferrado al antaño del siglo XIX, descompuesta y olvidada por las administraciones locales que solo han visto en ahora nueva estructura, un motor de captación de renta por revitalizar el sector de Belén, donde se encuentra actualmente ubicado.

En la actualidad, esta antigua cárcel presta otros tipos de servicios que no están estrictamente acordados desde el objetivo para su remodelación, es ahora, un sitio para el consumo de psicotrópicos y otras prácticas sociales como son la danza y el deporte; el Panóptico ha cumplido su papel como claustro de historias y de la cultura, aunque su interior aún debe ser renovado para culminar el objetivo de esta evaluarte obra arquitectónica del centro histórico de la ciudad y poder disfrutar de aquellos relatos que se construyeron espacialmente en nuestro centro histórico.

Finalmente, cabe precisar que el proceso de renovación de este anquilosado monumento ha permitido la concepción de un centro más abierto a la cultura de consumo, pues el revitalizar esta estructura desde una noción netamente política, ha llevado a ver con nuevos ojos el centro histórico de la ciudad, un centro más rentable y captador de plusvalías del suelo urbano. 


\section{Fotografía 9. Interior Panóptico, el olvidado interior del panóptico que no cumplió su objetivo como museo, foto actualidad}
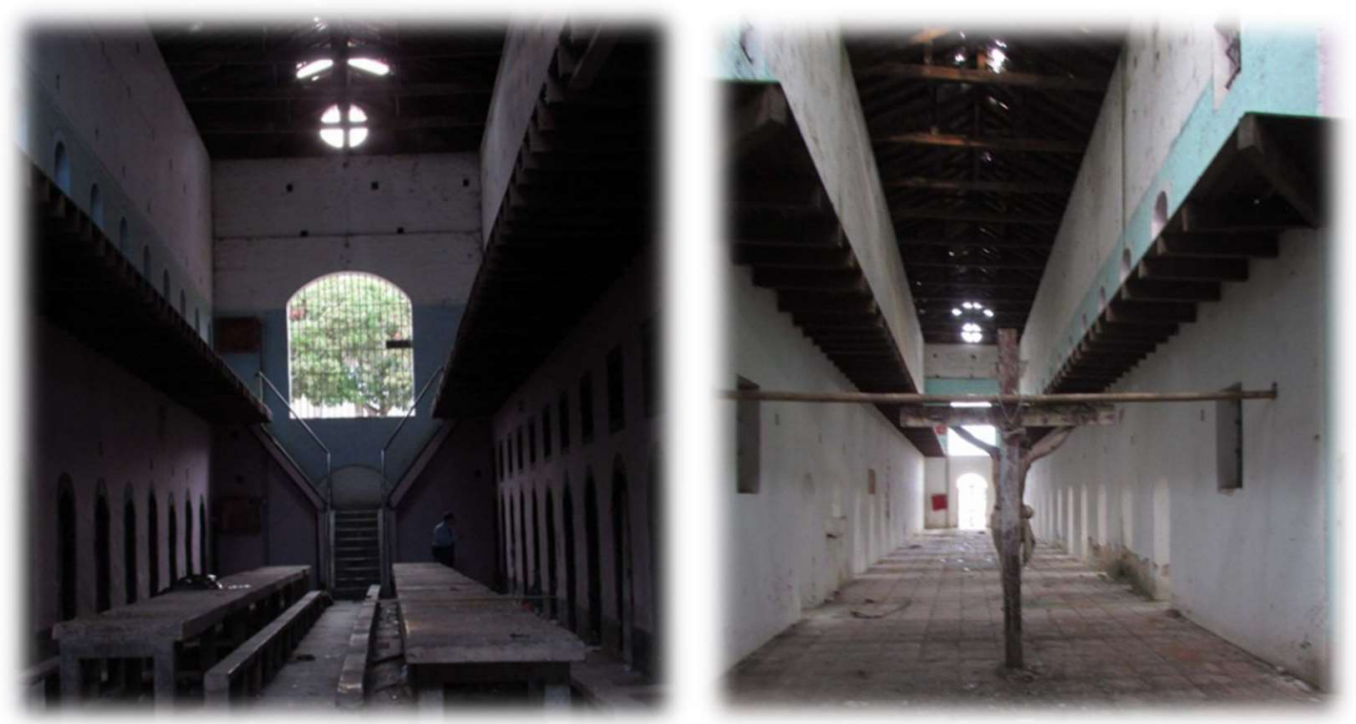

Autor: Julián Escobar (noviembre de 2015).

\section{Fotografía 10. Actual apariencia del Panóptico de la ciudad de Ibagué}

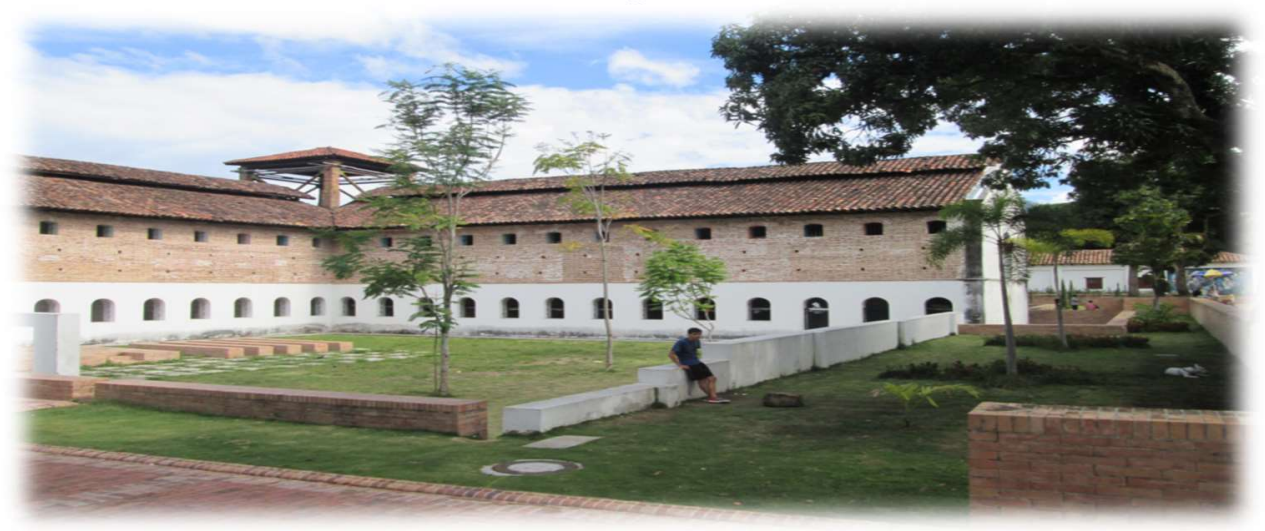

Autor: Julián Escobar (noviembre de 2015).

\section{SE RENOVÓ EL CENTRO ¿Y AHORA QUÉ?}

Como ya se ha mencionado, después del proceso de renovación estructural del espacio urbano de la ciudad, ya sea su centro histórico o no, comienzan a fluctuar constantemente las dinámicas del suelo urbano, estas fluctuaciones económicas en las dinámicas urbanas se generan de manera exponencial de acuerdo a las lógicas del mercado inmobiliario y el comercio de bienes y servicios a mediana escala, permitiendo llevar a cabo grandes y 
pequeños proyectos de inversión económica en lo que respecta el sector terciario de la economía, (bienes y servicios ) que encuentran en un espacio determinado por el capital, su mejor accionar para la producción y reproducción del mismo.

El centro histórico de la ciudad de Ibagué no escapa al fenómeno de tercerización que se ha gestado desde ya hace mucho tiempo, particularmente desde inicios del siglo XXI, posterior al proceso masivo de renovación urbana en el sector mencionado, en este sentido, el accionar político y administrativo tanto del sector privado como el público ha trabajado concomitantemente en aras de revitalizar y captar grandes plusvalías del centro histórico de la ciudad. De este modo, se entiende que se trata de un fenómeno antiguo, ya que según lo señalado por (Cobos, 2008), la tercerización en las ciudades de América Latina es el resultado paulatino de la desindustrialización en los viejos centros urbanos de las ciudades que fueron perdiendo el patrón de acumulación de capital industrial extrapolando dicha acumulación por la de bienes y servicios denotado a mediados de las crisis cíclicas del capitalismo de los años 80 (Cobos, 2008, p. 22). De igual manera, los autores afirman en que:

Hay quienes denominan desindustrialización este fenómeno; otros lo llaman tercerización. Pero cualquiera que sea la denominación, se trataría siempre de caracterizar el declive, relativo o absoluto, real o imaginario, del sector manufacturero y, en contrapartida, la ascensión del sector terciario (Cobos, 2008, p, 29).

Tratándose de una crisis de acumulación de capital, el mismo aparato capitalista, ingenia otros métodos igual o peor de sostenibles que los anteriores para seguir la cíclica vida del capital, evitando sin poder hacerlo, caer en contradicciones del sistema que sobre pasan la capacidad de volumen de capital vs trabajo; en este sentido, los centros urbanos, en nuestro caso el centro histórico de la ciudad, ha fortalecido su proceso de tercerización económica a partir del año 2000 en adelante, es decir, desde la implementación del P.O.T. que permitió engrosar durante el periodo de análisis las grandes inversiones por parte del capital privado y público en los sectores de servicios y de consumo.

Concurrir actualmente el centro histórico de la ciudad de Ibagué, es apreciar un proceso de tercerización o como lo denominaría los autores Lett Márquez Y Emilio Padilla "servilización" denotado durante los 15 años de análisis de este espacio urbano tan singular. Entre tanto, es frecuente observar y toparse con un sin número de bares bohemios, restaurantes, parqueaderos, tiendas artesanales, boutiques y centros de recreación establecidos por los mismos habitantes para pasar un rato en familia, o en el mejor de los casos, hacer deporte como es el caso del Skate Park de la ciudad en el antiguo barrio Pueblo Nuevo, o practicar el Parkour como se ha venido ejerciendo en el Panóptico de Ibagué; así mismo, el significativo aumento de vendedores ambulantes que están inmersos en el proceso de oferta de servicios informales, en breves palabras, un centro ya gentrificado. 
La dinámica de captación de plusvalías del suelo urbano terciarizado por parte del sector público puede acarrear una seria contradicción, pues al incrementar el costo sobre la propiedad directamente proporcional a la ganancia de servicios por parte de la pequeña empresa privada, se incrementa el valor de la tierra y modifica los usos de esta al antojo del sector privado (Amborski, 2003), aún más teniendo en cuenta que los afectados son la clase trabajadora, En este sentido, pues, las administraciones locales deben tener muy claro las políticas de contingencia ante una evidente especulación de los servicios ofertados en estos centros históricos; para el caso de Ibagué, se debe seguir constantemente el manejo del incremento de los servicios para que la clase trabajadora (la mayor consumidora) no se vea afectada por las irrisorias manifestaciones de acumulación de capital y los posibles emplazamientos de los residentes del sector por la alta oferta económica que afecta directamente el incremento de los servicios públicos del sector .

\section{Fotografía 11. Bares, boutiques y centros de servicio de ocio en el centro histórico de Ibagué}

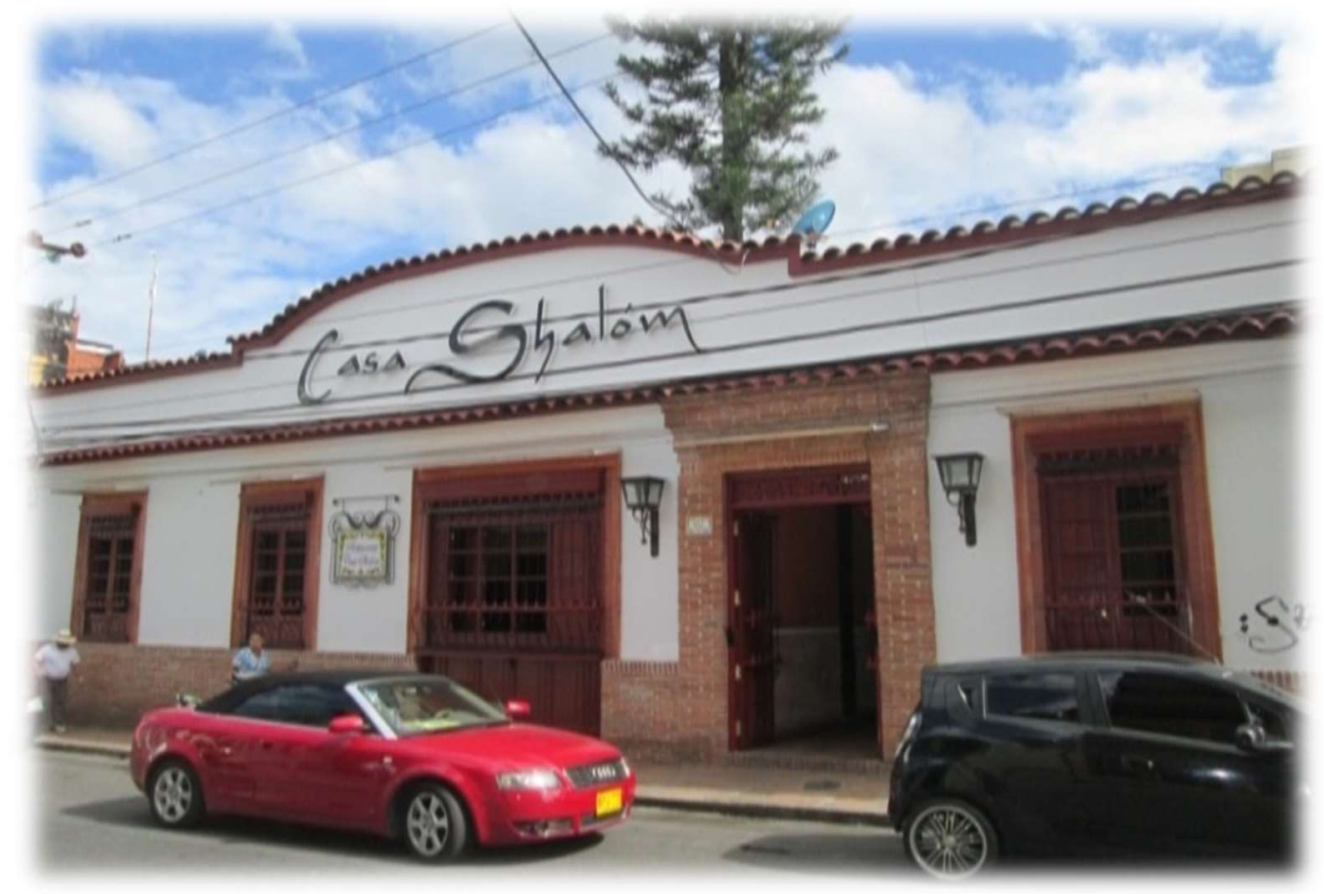

Autor: Julián Escobar (noviembre de 2015). 


\section{Fotografía 12. Bar Mayo Once}

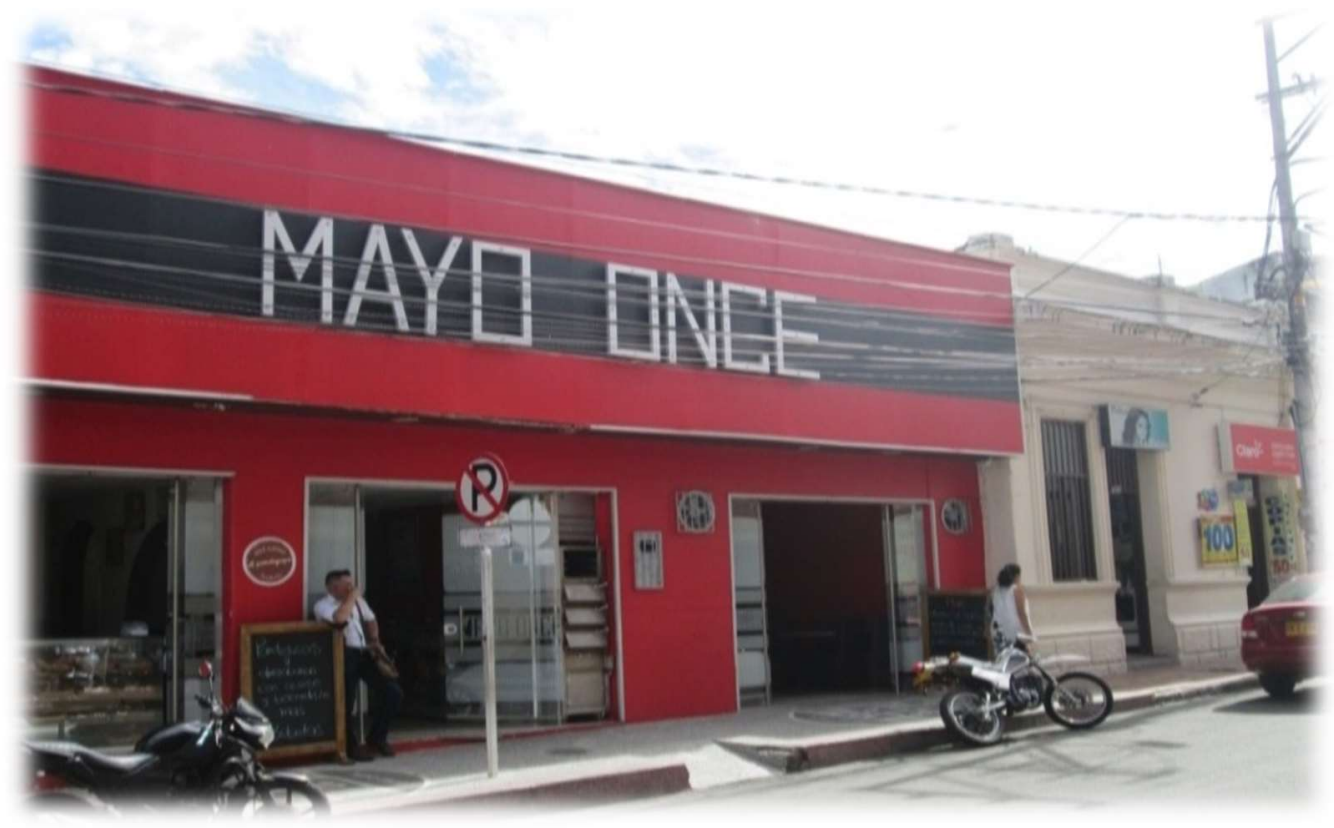

Autor: Julián Escobar (noviembre de 2015).

Ahora bien, no podemos dejar a un lado otros tipos de servicios que se ofertan de manera informal por parte de los vendedores ambulantes, pues ellos son una gran fuerza de las dinámicas microeconómicas del sector analizado y que, del mismo modo, hacen parte de una economía que determina en muchos casos la importancia del sector donde se concentre geográficamente los actores de esta economía tornadiza. Entendemos la economía informal urbana como lo señala (Sassen, 2003) "a aquellas actividades que generan ingresos fuera del marco regulatorio del estado que tiene analogías dentro de ese marco. El alcance y el carácter de esta economía informal se definen por el marco altamente regulatorio que evaden" (pág. 177). Principalmente, son estas economías las que abundan en los países sub-desarrollados a causa del impacto de las políticas neo-liberales en materia laboral, donde se concentra una gran masa de ejército de reserva industrial ${ }^{9}$ que son llevados a vender su fuerza laboral para y por ellos mismos. Sin embargo, hay quienes objetan radicalmente respecto al proceso de las economías informales que están determinadamente compuestas por la oferta de bienes y servicios y que tienen sustanciales impactos en el entramado del espacio público de las ciudades de américa latina (Londoño, 2006). Así pues, son las ciudades y en especial, sus principales centros urbanos los que concentran este grueso volumen de vendedores

\footnotetext{
${ }^{9}$ La reserva de ejercito industrial es según Marx, la masa de personas no trabajadoras que no modifican el carácter fundamental de la producción de capital dada la circunstancia de que no son contratados jurídicamente bajo un orden establecido de la venta de su trabajo, es decir, según la lógica del capitalista, son los más fáciles de explotar, esto lo podemos encontrar en el capítulo XXIII la ley general de la acumulación capitalista El capital Tomo I.
} 
informales que, de una manera $u$ otra, dinamizan los procesos socio económico de la ciudad capitalista.

\section{Fotografía 13. Boutiques en zona residencial del centro histórico de Ibagué}

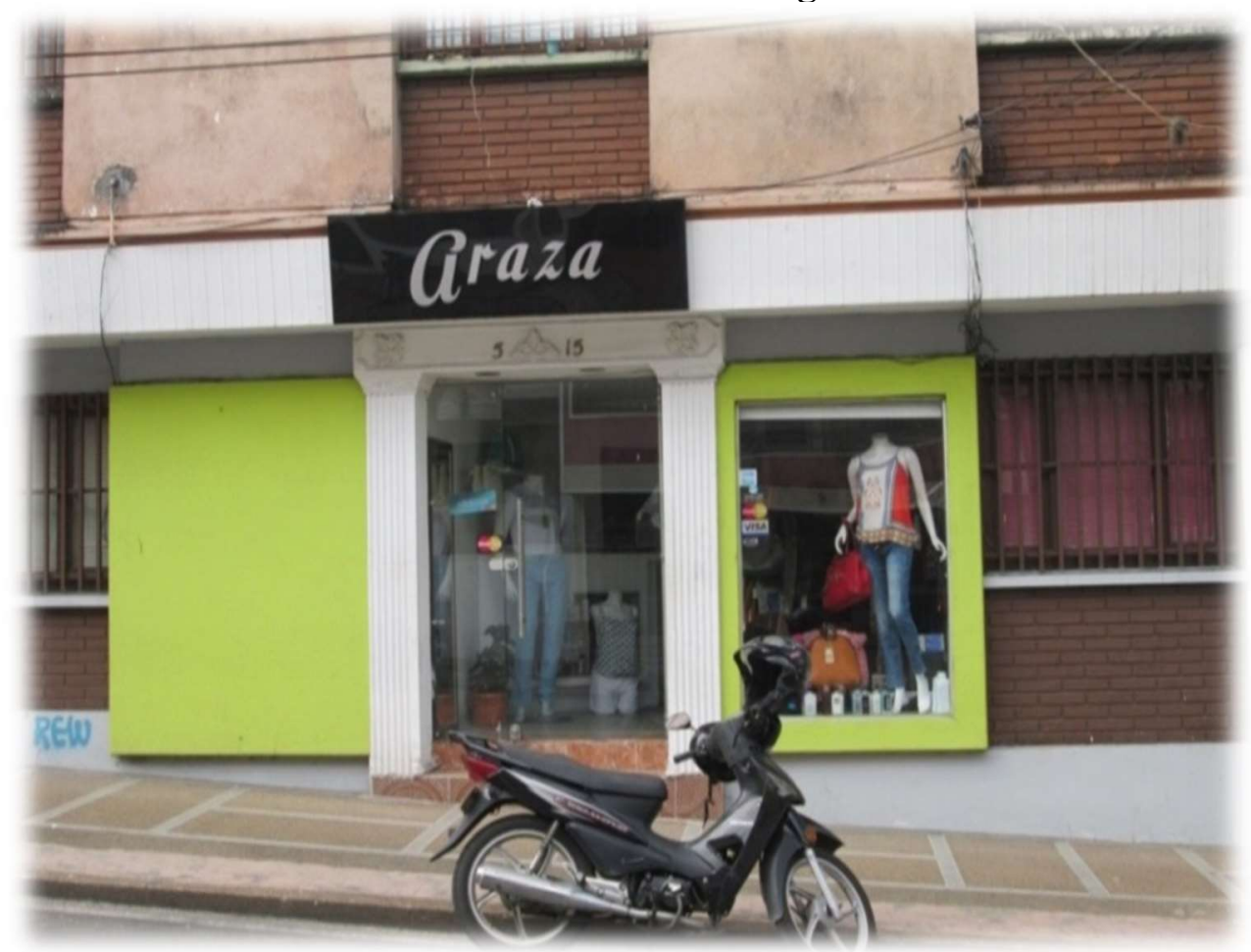

Autor: Julián Escobar (noviembre de 2015).

Figura 14. Skate Park del barrio pueblo nuevo

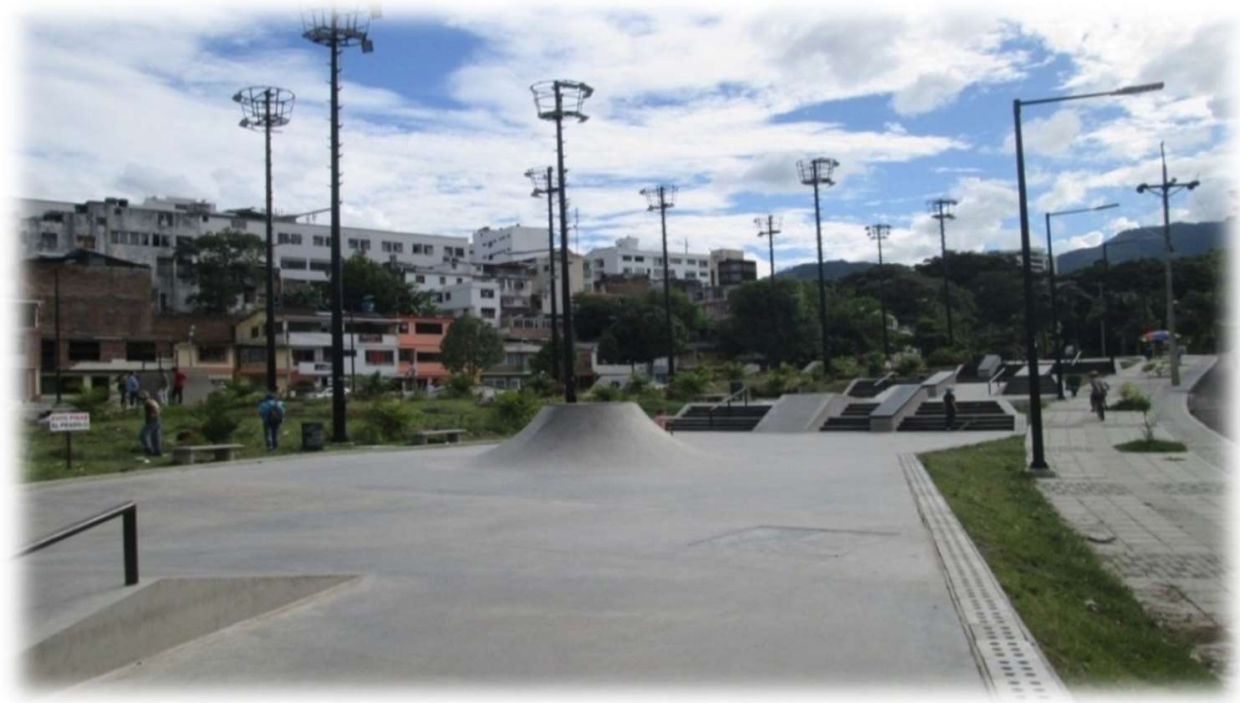

Autor:: Julián Escobar (noviembre de 2015). 
Por otro lado, desde un componente temporal, hemos podido constatar cómo el centro histórico de Ibagué ha sufrido estas transformaciones desde el año 2000 hasta el 2015 con la materialización del proyecto de renovación del panóptico, sin mencionar un buen número de proyectos; uno de ellos, el Museo de Arte del Tolima que fue inaugurado en el año 2003 en el barrio Belén del centro de la ciudad, trasformando esta zona desde un nivel más cultural y a su vez segregada por el abandono permanente de algunas edificaciones antiguas que dieron paso a nuevas estructuras modernas. Esto sin duda alguna ha llevado a una disputa entre capitales privados que han instalado su simbología de consumo superfluo en el centro de la ciudad, para convertirla como lo denominaría Sharon Zukin en "la moneda de intercambio comercial y el lenguaje de la identidad social” citado por Hanley (2008, p. 79).

Frente a este panorama, fue necesario tener en cuenta la perspectiva de algunos habitantes del centro histórico de la ciudad respecto a los procesos de renovación. En este sentido, se encuestó a 120 habitantes del sector a quienes se les realizó 1 pregunta, de las cual se enfocó a los procesos de renovación por parte de las administraciones locales. A partir de estas visiones, se puede clarificar de qué manera se ha manifestado el proyecto modernizador en el claustro histórico del centro de la ciudad; estos fueron los resultados.

La pregunta hace énfasis respecto al tiempo que se ha manifestado la renovación, esto contestaron los encuestados:

Figura 3. Percepción de los que los habitantes del centro histórico de Ibagué sobre los años de cambio urbanístico en el sector

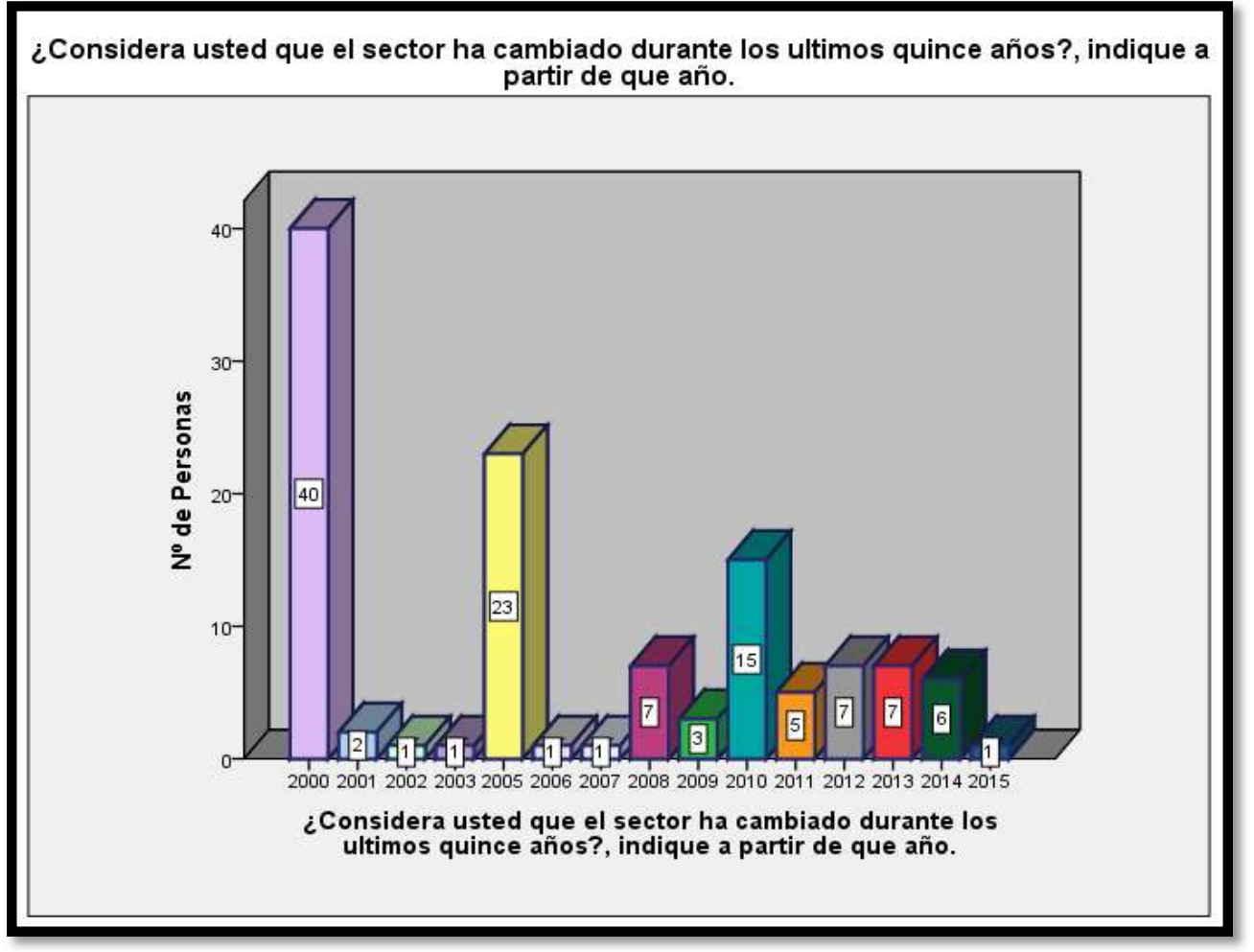

Fuente: Elaboración propia a través de encuesta realizada. 
Los resultados reafirman lo analizado en todo el grueso del artículo en tanto que muestra (según la percepción de los habitantes del sector) que el centro histórico de la ciudad se ha visto trasformado desde el año 2000-2005-2010, es decir, quinquenalmente. Como ya hemos señalado anteriormente, podemos apreciar unos cambios ejecutados a partir de las políticas públicas y privadas en materia de renovación urbana que se materializaron desde el año 20002005 años que concuerdan con la peatonalización de la carrera tercera y la renovación del Panóptico de la ciudad. Por otro lado, un buen número de habitantes señalan que desde el 2010 hasta el 2014 se vieron algunos cambios sustanciales en su espacio urbano, lo que demuestra unas dinámicas que no obedecen estrictamente a proyectos de renovación de algunos sitios emblemático de este sector si no, de dinámicas económicas en el entramado inmobiliario de la zona.

\section{REFLEXIONES FINALES}

La renovación en el sector se ha materializado durante los 15 años de análisis, en especial los primeros 8 años, esto permite esclarecer otros fenómenos intrínsecos al proceso de renovación a escala geohistórica del centro de la ciudad de Ibagué, como lo son, las dinámicas en los precios del suelo y la rentabilidad que ha adoptado este sector hacia la captación de plusvalías y la adulteración del espacio urbano por parte del capital privado y público que se ha podido manifestar con ayuda de las políticas públicas de la ciudad, trasformando drásticamente el paisaje urbano del centro de la ciudad y la misma percepción de los ciudadanos donde se ve reflejada la no interiorización de estas importantes dinámicas urbanísticas, de lo que evidentemente debería ser patrimonio de la ciudad.

Por otro lado, hay que entender de que la renovación urbanística del sector obedece a un proyecto macro de modernización urbana, como lo hemos analizado desde los componentes políticos externos, es decir, desde la ley 338 de 1997 y lo estipulado desde la política y ejecución entre sector privado y público, tal como lo recomendó la Cumbre HABITAT II, la renovación a escala urbana es una metodología para re-estructurar el capital en espacios degradados o poco rentables para la captación de plusvalías del suelo urbano, por tal motivo, según la experiencia a escala local, la inversión de capital con fines de renovación busca, evidentemente, la revitalización de estas zonas poco rentables para la apertura de servicios que permitan proyectar el centro histórico de la ciudad como un espacio de preferencia en inversión y consumo, y en la peor situación, un proceso irreversible de gentrificación.

A pesar de la alta inversión en materia de renovación urbana y los desfalcos económicos originados por la corrupción y burocratización administrativa, el centro histórico sigue en una constante trasformación urbanística, pues dicha corrupción ha llevado a que no se preserven aquellos lugares construidos en el lapso de los 15 años de análisis, lo que ha conllevado a otro tipo de apropiación de este espacio histórico por otros tipos de personas que no hacen uso de estos monumentos y calles que tuvieron un objetivo específico desde su construcción y renovación, y por lo tanto, un proceso masificado de terciarización. El abandono de estos monumentos, permiten otro tipo de prácticas económicas que se han mezclado con el afán de 
obtener rentabilidad del sector sin buscar una apropiación o identidad desde los ciudadanos y la constante construcción de este centro rico en historias tanto arquitectónicas como humanas. Por tal motivo, se hace imperativo seguir estudiando una sucesión de fenómenos urbanos que evidentemente están modificando el espacio vivido de todos los ibaguereños.

\section{BIBLIOGRAFÍA}

ABRAMO, M. R. Procesos Urbanos en acción ¿Desarrollo de Ciudades para todos? Buenos Aires: Ediciones Abya-Yala, 2016.

AMBORSKI, M. S. Recuperación de plusvalías para el desarrollo urbano: una comparación inter-americana. EURE, 2003, p. 55-77.

ARTASU, M. C. Gentrificacion y cultura: algunas reflexiones. Biblio 3W. Revista Bibliográfica de Geografía y Ciencias Sociales, 2011. p. 742-798.

BRÍÑEZ, N. R. Panóptico no logró pacto de cumplimiento. El nuevo Día, el periódico de los Tolimenses, 2008, p. 1.

BUTLER, G. R. Coming to Terms whit London: Middle class communities in a Global City. International Journal of Urban and Regional Research, 2001, p.70-87.

COBOS, L. M. Desindustrialización, terciarización y estructura metropolitana: un debate conceptual necesario. Cuadernos del CENDES, 2008, p. 21-45.

HANLEY, L. M. Centros históricos: espacios de rehabilitación y disputa. Organización Latinoamericana y del Caribe de Centros Históricos - OLACCH, 2008, p.78-84.

IBAGUE, A. D. Acuerdo 009 del 2002. Ibague: P. 2008.

LEY, D. Alternative Explanations for inner city Gentrification: A Canadian assessment. Annals of the Association of American Geographers, 1986, p. 521-535.

LONDOÑO, D. A. Espacio urbano y comercio en vía pública. Reglas, redes y uso del espacio público en la Ciudad de México. México D.F., 2006.

LUCAS, M. L. El proceso de renovación urbana en el barrio de La Boca (Buenos Aires). Vulnerabilidad y organización social. Prepared for Delivery at the 2001 Meeting of the Latin American Studies Association, Washington, 2001. p. 1-17.

MATINEZ, E. J. Paradigmas de intervención pública Latinoamericana en hábitat urbano. Montevideo: Departamento de Publicaciones, Unidad de Comunicación de la Universidad de la República (UCUR). 2011.

MATTOS, C. D. Movimientos del capital y expansión metropolitana en las economías emergentes Latinoamericanas. Revista de Estudios Regionales, 2001, nº 60, p. 15-43. 
MINISTERIO DE AMBIENTE, V. Y. Información práctica para formulación de Planes de Ordenamiento Territorial. Bogotá, 2003.

P.O.T. Plan de Ordenamiento Territorial de Ibagué, 2001.

PERIÓDICO EL NUEVO DÍA, e. p. En Vía de desarrollo. Tolima 7 días, 2003 p. 56.

RAMÍREZ, J. P. Uso del espacio público de la carrera tercera. Ibagué: Trabajo de grado como requisito parcial para optar a título de Magíster en Territorio, Conflicto y Cultura. 2014.

ROJAS, E. La preservación del patrimonio histórico urbano en América latina y el Caribe Una tarea de todos los actores sociales. Washington, D.C.: Banco Interamericano de Desarrollo, 2011.

SASSEN, S. Los espectros de la Globalización. Buenos Aires: Fondo de Cultura Económica, 2003.

SCHTEINGART, M. Problemas y políticas urbanas en América Latina. Certidumbres y falacias. Estudios Demográficos y Urbanos, 2007, vol. 22, no 3, p. 717-722.

SLATER, T. Gentrification of the City. The New Blackwell Companion to the City, 2011 p. 571-585.

PERIÓDICO EL TIEMPO. Peatones en la vía. El Tiempo, 2001, p. 1.

PERIÓDICO EL TIEMPO. Tolima. Peatonalización de la tercera. El Tiempo, 2003, p. 1.

WILLIAMS, N. S. Gentrification of the City. New York: Routledge Library Editions, 1986.

\section{RECURSOS ELECTRÓNICOS}

PERIÓDICO, R. El Parque de la Música, Patrimonio de la Humanidad. El nuevo Día, el periódico de los Tolimenses, 2012. Disponible en: $<$ http://www.elnuevodia.com.co/nuevodia/especiales/dia-de-los-inocentes/167469-el-parquede-la-musica-patrimonio-de-la-humanidad $>$. [Consulta: 16 de octubre de 2012].

PERIÓDICO EL TIEMPO. Antigua cárcel penitenciaria de Ibagué se convertirá en museo de los Derechos Humanos. El Tiempo, 2008 Disponible en: $<$ http://www.eltiempo.com/archivo/documento/CMS-4080797>. [Consulta: 23 de mayo de 2008]. 
(C) Copyright Julián Andrés Escobar Ávila y Revista GeoGraphos, 2018. Este artículo se distribuye bajo una Licencia Creative Commons Reconocimiento-NoComercial 4.0 Internacional.
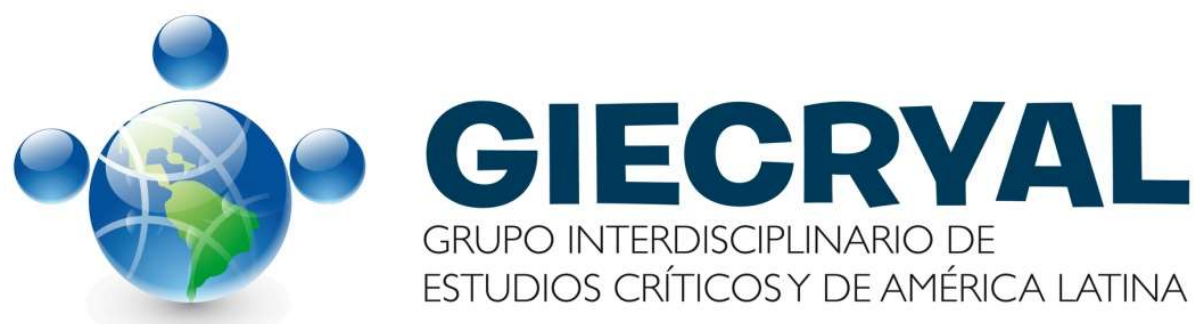

GRUPO INTERDISCIPLINARIO DE

ESTUDIOS CRÍTICOSY DE AMÉRICA LATINA 